\title{
Factors Governing onset of Local Instabilities in Fire Exposed Steel Beams
}

\author{
M.Z. Naser ${ }^{1}$, V.K.R. Kodur ${ }^{2, *}$ \\ Department of Civil and Environmental Engineering, Michigan State University, East Lansing, \\ MI, USA.
}

\begin{abstract}
This paper presents critical factors that influence the onset of local buckling in steel beams when exposed to fire conditions. A three-dimensional nonlinear finite element model, capable of accounting for critical factors that influence local instability in fire exposed steel beams is developed. This model is applied to investigate the effect of beam-slab interaction, strength properties (Grade) of steel, and presence of fire insulation on the onset of local instability, and resulting capacity degradation in fire exposed steel beams. Results from numerical simulations are utilized to evaluate failure of beams under different limit states including flexure, shear, sectional instability and deflection. These results infer that web instability can occur at early stages of fire loading, leading to faster degradation of shear capacity and premature failure of steel beams before attaining flexural capacity. Also, results from the analysis indicate that the contribution of concrete slab to shear capacity can counterbalance the adverse effect of web local instability to a certain degree. Overall, neglecting the effect of fireinduced web local instability can lead to unconservative design in steel beams or girder subjected to high shear loading and/or local instabilities.
\end{abstract}

Keywords: Local buckling, fire resistance, steel beam, shear, composite action, fire insulation, finite element analysis

\footnotetext{
${ }^{1}$ Ph.D. Candidate, Civil and Environmental Engineering, Michigan State University, Email: nasermoh@msu.edu

2,* Professor, Civil and Environmental Engineering, Michigan State University, Email: kodur@egr.msu.edu 


\subsection{INTRODUCTION}

In current practice, steel beams are to be designed to satisfy flexural, shear and serviceability limit states [1]. In ambient design, one of the key factors that need to be satisfied in achieving required moment and shear capacity is local buckling limitations. However, in current fire design provisions, only moment capacity at a given fire exposure time is utilized to evaluate failure of steel beams under fire loading without giving any due consideration to shear and sectional instability. Although deriving failure of beams based on flexural limit state is valid in most application and loading scenarios, this assumption may not be representative in certain situations where shear and instability (i.e., web local buckling) effects can be dominant in a fire exposed member [1].

Shear effects can be dominant under certain loading scenarios such as beams with concentrated loads acting at interior or end supports, as in the case of beams connecting offset columns in a building and transfer beams. In addition, temperature-induced buckling of web can be a governing factor in steel structural members with certain geometrical features i.e., beams with coped ends, deep beams and plate girders (with slender webs) [2-6]. Since webs are typically much more slender than flanges, larger surface area of web gets exposed to fire, leading to rapid rise of temperature in webs [1]. The faster rise in web temperatures leads to rapid degradation in strength and stiffness properties. This can initiate local buckling in web at lower steel temperatures and accelerate failure of beams.

Temperature-induced sectional instability in fire exposed steel beams results from the built-up of internal compressive stresses due to applied loading, and also due to rapid degradation in strength and modulus properties of steel with temperatures. When these built-up stresses reach the plastic limit, sectional instability is said to occur. Occurrence of such 
instability reduces effective area, which in turn decreases available flexural and shear capacity under fire conditions. In fire exposed beams subjected to high shear forces, a combination of temperature-induced strength degradation (in web) and earlier onset of local instability due to temperature-induced web local buckling can cause failure of beams in "Shear" before attaining flexural capacity.

The effect of local buckling on the response of fire exposed steel members was studied by some researchers [7-9]. For instance, Uy and Bradford [7] studied local buckling of coldformed steel structural members at elevated temperatures using the finite strip method. The authors reported that the degradation in properties of steel at elevated temperatures can influence local buckling in steel-concrete composite construction. Zhao and Kruppa [8] performed fire tests on fire exposed steel composite beams and reported that steel beam sections classified as compact (at room temperature) can undergo local buckling under high temperature exposure.

In a recent study, Kodur and Naser developed a three dimensional finite element model to study the shear response of fire exposed steel beams [1]. The authors investigated the effect of different loading patterns, web slenderness and presence of fire insulation on steel beams subjected to high shear loading and exposed to fire conditions. Based on results from numerical studies, Kodur and Naser reported that shear capacity can degrade at a much higher pace than flexural capacity, thus leading to premature failure under shear limit state. This shear failure is initiated prematurely due to local buckling in the web which can occur at early stages of fire loading. The authors showed that this failure may occur under certain loading conditions, such as in beams loaded with high shear forces near end or interior supports. 
The beneficial effect of composite action is generally accounted for in evaluating flexural capacity at room temperature. Yet, in current provisions (AISC) of composite beam-slab assemblies, shear capacity is evaluated based on contribution of web only, without any consideration to contribution from concrete slab of composite beam-slab assemblies [10]. Similarly, Eurocode 4 provisions state that resistance to vertical shear should be taken as the resistance of the structural steel section alone (web) "unless the value for a contribution from the reinforced concrete part of the beam has been established" [11]. Hence, any contribution of reinforced concrete (RC) slab through composite action is neglected in evaluating shear capacity.

Although current design provisions neglect the positive contribution of concrete slab, experimental evidence suggests otherwise [12-14]. For instance, Johnson and Willmington studied the shear capacity of composite beams in the negative moment regions and reported that the concrete slab contributes $20-40 \%$ of the total shear capacity [12]. Shear capacity of composite steel beams was also studied by Nie et al. [13] through tests on 16 composite beams and two individual steel beams at ambient conditions. The authors reported that steel-concrete composite beams designed with full shear transfer between steel beam and concrete slab can develop much higher shear capacity as compared to plain steel beams. Also, it was found that the contribution of the concrete slab can enhance shear resistance by 33-56\%. The above studies clearly show that current code provisions underestimate the shear capacity of composite beams by neglecting the positive contribution of concrete slab.

Unfortunately, the effects of local instability and composite action on fire response of steel beams were not considered in earlier studies. In order to bridge this knowledge gap, a numerical study is carried out using a three-dimensional nonlinear finite element model. The developed model can trace fire response of steel beams subjected to significant bending moment 
and shear loading. The model is applied to examine the effect of beam-slab interactions, strength properties (Grade) of steel and fire insulation on the onset of local instability in steel beams exposed to fire.

\subsection{EFEFCT OF LOCAL BUCKLING ON FLEXURAL AND SHEAR CAPACITY}

Adverse effect of local buckling on the response of steel beams is taken into account in evaluating flexural and shear capacity at room temperature [10, 11]. For instance, the AISC design manual classifies cross-sectional shapes as compact, non-compact and slender based on sectional slenderness (width-to-thickness ratio $\lambda$ ) of flange and web. This sectional slenderness ratio is usually compared against two upper limits to classify the shape of the section: compact $\left(\lambda_{p}\right)$ and non-compact $\left(\lambda_{r}\right)$. These upper limits are a function of strength and stiffness properties $\left(\sqrt{\frac{E}{f_{y}}}\right)$ of steel.

Under fire conditions, local buckling can occur once strength and stiffness properties start to degrade with rise in steel temperature. Onset of local buckling can induce further degradation in flexural and shear capacity of beams under fire conditions. Strength and stiffness properties of steel start to degrade at different rates after about 400 and $150^{\circ} \mathrm{C}$, respectively (see Fig. 1). Hence, local buckling can occur at earlier stages of fire, even before strength properties starts to degrade. Therefore, capacity degradation in steel beams can arise from temperature-induced web local buckling $\left(\right.$ at $150^{\circ} \mathrm{C}$ ) followed by degradation of strength properties (at $400^{\circ} \mathrm{C}$ ) [1].

Figure 2 illustrates how the width-to-thickness classification limits of Grade 50 steel (345 MPa) change with elevated temperatures. Slenderness limits generally decrease as a function of temperature. However, flange slenderness limit, used in flexural evaluation, tends to be stable 
and experience slight fluctuation at elevated temperature (see Fig. 2). It can also be seen in the figure that web slenderness limits (for shear evaluation) vary over a smaller range $(59 \leq \lambda \leq 77)$ than the flange slenderness limits used in shear calculation $(90 \leq \lambda \leq 137)$. Thus, fire exposed steel beams are more sensitive to local buckling in web than that in flange.

Sectional slenderness (width-to-thickness ratio $\lambda$ ) depends only on the geometrical features (dimensions) of a section. Thus, flange and web slenderness ratios ( $\lambda_{\text {flange }}$ and $\left.\lambda_{\text {web }}\right)$ of a given shape remain invariant even under fire exposure. Since width-to-thickness classification limits decrease at high temperature, the constant value of flange and web slenderness ratios ( $\lambda_{\text {flange }}$ and $\lambda_{\text {web }}$ ) can exceed that of the degraded width-to-thickness classification limits. Once flange and/or web slenderness ratios exceed corresponding classification limits, temperatureinduced local buckling is said to occur. Therefore, classification of a fire exposed steel section can change from that at room temperature.

To illustrate this, a W16×31 beam section made of Grade 50 (345 MPa) steel with web slenderness $\left(\lambda_{\text {web }}\right)$ of 57.8 is selected. When comparing this web slenderness with the web slenderness limit $\left(\lambda_{w p}\right)$ of Grade $50(345 \mathrm{MPa})$ steel at room temperature $\left(\lambda_{w p}=1.10 \sqrt{\frac{k_{v} E}{f_{y}}}=\right.$ 59.24), this beam falls under "compact" section category. However, when comparing web slenderness of the same section against the web slenderness limit at $500^{\circ} \mathrm{C}\left(\lambda_{w p}\right.$ at $\left.500^{\circ} \mathrm{C}=51.9\right)$, the web slenderness of a W16×31 section clearly exceeds that of web slenderness limit $\left(\lambda_{w p}\right)$ at $500^{\circ} \mathrm{C}$. Thus, the beam is classified as non-compact when steel temperatures reach $500^{\circ} \mathrm{C}$. On the other hand, the flange slenderness of the same section $\left(\lambda_{\text {flange }}\right)$ is 6.28 . This slenderness ratio remains below the corresponding limit $\left(\lambda_{f p}=0.38 \sqrt{\frac{E}{f_{y}}}=9.15\right)$ even at temperatures of $500^{\circ} \mathrm{C}$ and 
beyond $\left(\lambda_{\text {pat } 800^{\circ} \mathrm{C}}=8.03\right)$. Therefore, flanges of a $\mathrm{W} 16 \times 31$ beam section remain compact even at elevated temperatures.

Current design provisions in codes and standards provide no recommendations for classification of steel sections under fire conditions, based on a local buckling criterion. This implies that if a section is compact at ambient conditions, it continues to be compact under fire conditions. From the analysis shown above, it is clear that current provisions may not lead to the same section class classification of steel beams under fire conditions.

\subsection{FINITE ELEMENT MODEL}

To study the effect of local buckling on the response of steel beams under fire conditions, a three dimensional nonlinear finite element model was developed in ANSYS 14.0 [15] to trace the realistic response of fire exposed steel beams. This model accounts for critical parameters that influence sectional instability, including geometric and material nonlinearities, composite action arising from the concrete slab, temperature dependent material properties and various failure limit states.

\subsection{Discretization of beam}

The three dimensional finite element model, is capable of tracing thermal and structural response of fire exposed steel beams from pre-loading stage till failure of the beam. In order to simulate the realistic response of fire exposed steel beams, the developed model was discretized using various element types available in ANSYS 14.0 [15]. These element types can simulate both thermal and structural behavior associated with fire exposed steel beams.

SHELL131, SOLID70, LINK33 and SURF152 elements are used as thermal elements to simulate heat transfer between steel girder and fire source [15]. SHELL131 is a 3-D layered shell 
element having in-plane and through-thickness thermal conduction capability. SOLID70 is an eight-node (cubic) thermal element with conduction capability. LINK33 is a uniaxial (bar) element with the ability to conduct heat between its nodes for a single degree of freedom; temperature. SURF152 is a four-node (surface) thermal element capable of simulating heat conduction, convection and radiation. SURF152 is overlaid on top of SHELL131 and SOLID70 elements to simulate convection and radiation effects from fire zone to steel beam. In order to simulated the convection and radiation mechanism, a convection coefficient $\alpha_{\mathrm{c}}=25 \mathrm{~W} /\left(\mathrm{m}^{2 \circ} \mathrm{C}\right)$ and Stefan-Boltzmann radiation constant of $5.67 \times 10^{-8} \mathrm{~W} /\left(\mathrm{m}^{2 \circ} \mathrm{C}\right)$ were considered in the thermal analysis.

For discretizing the steel beam to be analyszedd, SHELL181, SOLID65, LINK8, COMBIN14, COMBIN39, BEAM188, CONTA173 and TARGE170 elements are utilized. SHELL181, used to model the steel beam, has four nodes with six degrees of freedom (three translations and three rotations) per node. This element can capture local buckling of flanges and web and also lateral-torsional buckling of this steel beam and therefore is well-suited for large rotation, large strain and nonlinear problems. SOLID65 is used for three-dimensional modeling of solids with or without reinforcing bars (such as the concrete slab). SOLID65 is capable of accounting for concrete cracking in tension and crushing in compression.

LINK8, used to model steel reinforcement in the concrete slab, is a two-node uniaxial tension-compression link element with three degrees of freedom (translations) at each node. This element is used to model the internal (steel) reinforcement embedded in the concrete slab. COMBIN14 and COMBIN39, are spring-like elements and are used to simulate the bond between steel reinforcement and surrounding concrete, and between shear studs and concrete slab, respectively. BEAM188, used to model shear studs, is a three dimensional two-node beam 
element that has six degrees of freedom at each node: translations along the principal axes and rotations about the principal axes [15]. The shear studs (BEAM188 elements) are embedded in the concrete slab and are assumed to be connected to the surrounding concrete. Thus, the nodes of BEAM188 elements are coupled with the nodes of concrete elements (SOLID65). These elements are also fully connected to the steel beam top flange. At the interface between shear studs and steel beam, the coinciding node of BEAM188 and SOLID65 elements were connected using spring elements (COMBIN39).

In addition, the contact behavior at the interface of concrete slab and top flange of the steel beam was modeled using CONTA174 and TARGE170 elements. The contact interface is defined as surface-to-surface area that only allows sliding of the two adjacent faces. The amount of sliding is governed by Coulomb's frictional law and a coefficient of friction of 0.35 was assumed. The element used in structural analysis as well as a discretized view of the developed model is shown in Fig. 3.

\subsection{High temperature material and constitutive laws}

For undertaking fire resistance analysis, temperature-dependent thermal and mechanical properties of steel, concrete and fire insulation are to be inputed to the finite element model. The thermal and mechanical properties of structural steel, concrete and reinforcing steel are assumed to vary with temperature as per Eurocode 3 and 2 relations [15-18]. For fire insulation, room temperature thermal properties are used in fire resistance analysis since there is very limited information on variation of thermal properties with temperature. The room temperature thermal conductivity and specific heat of fire insulation are $0.0815 \mathrm{~W} / \mathrm{m} .{ }^{\circ} \mathrm{C}$ and $1047 \mathrm{~J} / \mathrm{kg} . \mathrm{K}$, respectively. 
For steel, a multi-linear stress-strain relationship, with kinematic hardening plasticity, as obtained using Eurocode 3 model, is used. This constitutive material model consists of multiple stress-strain curves that vary with temperature (as shown in Fig. 4a). In order to define the plastic behavior of the concrete, ANSYS uses a constitutive material model formulated by William and Wranke [19]. Concrete is assumed to follow a nonlinear parabolic behavior in compression, as described in Eurocode 2, and is treated as an isotropic elastic material until it cracks (as shown in Fig. 4b). Once a concrete element cracks, the tensile softening behavior is modeled using a trilinear response. The tensile response starts with an ascending linear-elastic regime until it reaches the ultimate tensile strength $\left(f_{t}\right)$. Once the ultimate tensile strength is reached, concrete tensile strength drops to $\left(0.6 f_{t}\right)$ then softens in a descending manner gradually to zero. Further, the concrete model requires additional parameters: open and close crack shear transfer coefficients $\beta_{t}$ and $\beta_{c}$. These shear transfer coefficients are generally used to account for shear stiffness retention in cracked concrete elements and range from zero to one representing smooth and rough cracks, respectively. The values of $\beta_{t}$ and $\beta_{c}$ used in the developed model are 0.2 and 0.7 , respectively.

In order to accurately model the interface between reinforcing steel rebars and surrounding concrete, the corresponding longitudinal bond-slip is modeled using COMBIN14 elements. COMBIN14 elements require a value for the longitudinal stiffness $(k)$ which is obtained from the secant of equation (2) (derived by Nie et al. [20]);

$$
k=\frac{\pi}{s_{u}} p d_{r} N_{r} \tau_{u}\left(\frac{L_{1}+L_{2}}{2}\right)
$$


where, $p$ is the horizontal distance between the tension steel reinforcement bars (in $\mathrm{mm}$ ), $d_{r}$ is the diameter of the steel bars (in mm), $N_{r}$ is the number of reinforcing bars and $L_{1}$ and $L_{2}$ represent the lengths of two adjacent reinforcement elements (LINK8) (in mm).

To account for shear force-slip between shear studs and concrete slab, a nonlinear constitutive relationship suggested by Ollgaard et al. [21] is used.

$$
Q=Q_{u}\left[1-e^{-4.75 s}\right]
$$

where $Q$ is the shear force, $Q_{u}$ is the strength of the studs calculated as $Q_{u}=0.43 A_{s} \sqrt{E_{c} f_{c}} \leq 0.7 A_{s} f_{u} ; A_{s}, E_{c}, f_{c}$ and $f_{u}$ are cross sectional area of the shear studs, elastic

modulus of the concrete taken as $4600 \sqrt{f_{c}}$ (in MPa), compressive strength of the concrete, and ultimate strength of the studs taken as $420 \mathrm{MPa}$, respectively. $S$ is slip length and the maximum slip length was set to $1.27 \mathrm{~mm}$ [22]. The outcome of this relationship is used to supply the required shear force and slip behavior of shear studs modeled using COMBIN39 elements.

\section{$\underline{3.3 \text { Failure limit states }}$}

The failure of a beam under fire conditions can occur in different modes and the evaluation of realistic failures requires different end failure criteria. In this analysis, all possible different failure limit states, including flexural, shear, local buckling and deflection, are considered for evaluating failure of the beam at each time step. Failure is said to be reached once any of these failure limit states is exceeded. For example, moment and shear capacity at any time step are evaluated utilizing internal bending and shear stresses generated from ANSYS analysis. These stresses, generated at individual elements, were integrated across the depth of the section. The integration process requires a supplementary sub-routine to extract generated internal 
stresses to arrive at moment and shear capacities at each time step. These internal moment and shear capacities are compared against flexural and shear limiting criteria. Failure is said to occur under a flexural or shear limit state once the bending moment (or shear force) due to applied loading exceed the moment (or shear) capacity at a critical section.

In addition, the local buckling limit state is also checked at each time step by updating the slenderness limits which change with the steel temperature. In addition, slenderness of flanges and web is updated and checked against flexural and shear slenderness limits at different steel temperatures (time steps). Once the sectional slenderness exceeds the degraded slenderness limit $\left(\lambda_{p}\right.$ or $\lambda_{r}$ ), local buckling is said to occur and sectional capacity is adjusted to account for the loss arising from local buckling. Finally, a deflection limit state is also applied to evaluate failure of fire exposed beams. When the beam attains a deflection of $L / 20$ or rate of deflection reaches $L^{2} / 9000 d$, where $L$ and $d$ are the span and depth of the beam, respectively, the beam is said to attain failure [23].

\subsection{MODEL VALIDATION}

Since there is lack of published experimental data on steel beams subjected to high shear forces, the above finite element model was validated using data from tests on conventional steel beams. Kodur and Fike [24] have conducted a fire resistance test on a 4 m long W12×16 A992 steel beam under ASTM E119 standard fire (see Fig. 5). The beam was insulated with $50 \mathrm{~mm}$ thick fire insulation to achieve a 2-hr fire resistance rating. The beam was loaded up to 31\% of its flexural capacity using two point loads near mid-span.

The tested beam is analyzed using the above developed model and temperatures, the midspan deflection, moment and shear capacity, and failure mode generated in the analysis are 
compared against measured test data. For instance, Fig. 6a shows comparison of predicted and measured temperatures in the steel beam as a function of fire exposure time. It can be seen that the average of both flanges and web temperatures in the steel section rises slowly due to the presence of fire insulation. These temperatures continue to rise until failure of beam. Predicted temperatures plotted in Fig. 6a shows good agreement with measured temperatures up to the first 45 minutes of fire test (when steel reaches $350^{\circ} \mathrm{C}$ ). Then, this predicted temperatures tend to be slightly higher than the measured data points until 100 minutes into the fire test. It should be noted that such variation can be related to differences in assumed and actual thermal properties of fire insulation at elevated temperatures. Towards the end of fire test, both measured and predicted temperatures converge at temperatures around $690^{\circ} \mathrm{C}$.

A comparison of predicted and measured mid-span deflection response of the tested steel beam is shown in Fig. 6b. In the first 90 min, the beam experiences small deflections, due to the low rise of temperature in the insulated steel beam. However, as the temperature in the steel beam reaches $550^{\circ} \mathrm{C}$ (at about $100 \mathrm{~min}$ ) strength and stiffness properties of steel experience faster degradation which leads to a rapid rise in deflection. After two hours of fire exposure, steel loses most of its strength and stiffness as the temperature of the beam rises to $600^{\circ} \mathrm{C}$. This significant loss of strength and stiffness properties leads to rapid rise in deflections and produces runaway failure of the beam at 122 min. Further details on this validation process can be found elsewhere [1].

For this beam, degradation of moment and shear capacity with fire exposure time at corresponding critical sections; mid-span section for moment and support section for shear are shown in Fig. 7. The moment capacity of the beam remains intact for the first 75 minutes due to the lower temperatures (much below than $350^{\circ} \mathrm{C}$ ) in the steel beam flanges. However, the shear 
capacity starts to degrade at 35 min due to relatively faster rise in web temperature. Then, moment and shear capacity starts to degrade when the temperature in the steel section reaches $400^{\circ} \mathrm{C}$. Degradation of the moment capacity of the steel section continues till $130 \mathrm{~min}$, at which the beam fails. This beam fails because its moment capacity at mid-span falls below the moment due to applied loading. Since the beam was subjected predominantly to flexural loading, the resulting applied shear force does not fall below shear capacity near the vicinity of the support sections. Hence, as per the analysis, failure of this beam occurs due to flexural effects at 130 min, while the correspondingly failure of this beam in fire test occurred at $122 \mathrm{~min}$. This comparison in response trends clearly indicate that the above developed model is capable of tracing reasonably well the response of beams under fire conditions.

It should be noted, that there is lack of fire test data in the literature on beams with high levels of shear loading. To overcome this knowledge gap, the authors are currently undertaking a series of full scale fire tests on steel beams by subjecting them to high shear loading. The outcome of this experimental program will be used to further validate the developed finite element model and then generate various parametric studies on the different factors that influence sectional capacity and stability response of fire exposed steel beams subjected to high shear loading.

\subsection{CRITIAL FACTORS GOVERNING LOCAL BUCKLING UNDER FIRE CONDITIONS}

The validated finite element model was applied to study the effects of beam-slab interaction, strength properties (Grade) of steel and fire insulation on the onset of local instability and capacity degradation in steel beams exposed to fire. Results from finite element analysis are examined to evaluate failure of beams under different failure limit states including flexure, shear, 
sectional instability and deflection criteria, but due consideration was given to isolate the effect of sectional instability.

\subsection{Analysis details}

The beam selected is a simply supported beam of W16×31 section fabricated from Grade $345 \mathrm{MPa}$ steel and taken from the AISC design manual [10]. The flange width is $140.6 \mathrm{~mm}$ and the overall depth of this section is $404 \mathrm{~mm}$, while the corresponding flange and web thicknesses are 11.2 and $7 \mathrm{~mm}$, respectively. The beam is subjected to combined bending and shear loading, and exposed to ASTM E119 fire. To simulate high shear loading, a uniformly distributed loading (UDL), across the whole span of the beam, and two concentrated loads close to supports are applied as shown in Fig. 8.

In order to simulate the response of fire exposed steel girders, two stages of analysis are to be carried out at each time step. The first stage simulates the heat transfer between the fire source and beam-slab assembly. In this stage, temperature profiles and thermal gradients are generated based on the fire scenario the girder is exposed to. Once sectional temperatures are generated from thermal analysis, they are inputed to the second stage of fire analysis. Both temperature and loading are applied simultaneously to the second stage of fire analysis to carry out the structural analysis. In the structural analysis, mechanical responses such as mid-span deflection, stress, strain and stability states, along with sectional capacity of fire exposed beam, are evaluated.

As part of the numerical study, the effects of three main parameters are studied, namely the effect of beam-slab interactions, strength properties (Grade) of steel and presence of fire insulation on the onset of local buckling of steel girders exposed to fire conditions. In order to vary critical parameters, seven beams, with varying characteristics, are analyzed and the 
variables are shown in Table 1. All beams were exposed to the ASTM E119 standard fire exposure scenario.

\section{$\underline{5.2 \text { Effect of composite action }}$}

In beam-slab composite assemblies both the steel beam and concrete slab contribute to resist the applied loading through composite action. The beneficial role of composite action on flexural response at ambient conditions is well established and is accounted for in the AISC manual and Eurocode design provisions. However, despite experimental evidence, the contribution of composite action is not taken into account when evaluating the shear capacity and local buckling in composite assemblies [5-9, 25]. The effect of composite action arising from the presence of the concrete slab on the onset of local buckling in fire exposed steel beams is studied herein by analyzing a bare steel beam, "Beam 1" (without any composite action), and a composite beam "Beam 2" under fire conditions. The concrete slab considered in "Beam 2" has width $1145 \mathrm{~mm}$ and thickness of $115 \mathrm{~mm}$. Also, in this beam, full composite action between the steel beam and concrete slab is facilitated by providing fourty $1 / 2 \times 2 \frac{1}{2}$ shear studs as per the AISC provisions. These studs are placed symmetrically in two rows and spaced by $229 \mathrm{~mm}$ (center-tocenter). These shear studs have an ultimate tensile strength of $420 \mathrm{MPa}$ and a shear capacity of $51.6 \mathrm{kN}$.

In the analysis, "Beam 2" was subjected to the same loading used in "Beam 1" (see Fig. 8) and exposed to the ASTM E119 fire. Generated thermal results from this analysis are shown in Fig. 9. These results show the predicted temperature progression in the steel beam web, as well as in the concrete slab at a depth of $50 \mathrm{~mm}$ and at the top surface. Temperatures in both steel beams (Beam 1 and Beam 2) rise rapidly after the first 8 min of fire exposure. Nevertheless, the temperature progression in the concrete slab increases at a much lower rate due to better 
thermal inertia of concrete (much lower thermal conductivity and higher heat capacity). At 30 minutes into fire exposure, temperatures in the concrete slab remain below $380^{\circ} \mathrm{C}$ at depth of 50 $\mathrm{mm}$ and below $220^{\circ} \mathrm{C}$ at the top surface. Thus, the concrete slab continues to contribute to the moment and shear capacity, especially once much of the steel strength and stiffness are lost due to the increasing temperatures.

In order to further analyze Beams 1 and 2, the degradation of the flexural and shear capacity (at critical sections) with the fire exposure time in these beams are plotted in Fig. 10. It can be seen from Fig. 10a that the presence of the concrete slab greatly enhances the moment capacity of the composite beam at ambient and fire conditions. Accounting for composite action increased the overall moment capacity at room temperature by 55\%. Concerning the flexural limit state, the flexural failure occurs earlier in "Beam 1" (14 min) than in "Beam 2" (28 min).

Figure 10b shows the shear response of Beams 1 and 2. As mentioned earlier, the AISC provisions assume the web of the $\mathrm{W}$-shaped section to provide full shear resistance to the applied loading and ignores the contribution of concrete (slab) to the shear capacity. According to these provisions, both Beams 1 and 2 have similar shear capacity and are to fail at the same time. However, the results from the analysis show that failure of Beams 1 and 2 occurs at different times. In order to distinguish the effect of web local buckling on the response of Beams 1 and 2, two scenarios are plotted in Fig. 10b accounting for local buckling of web (WLB) and not considering local buckling (no WLB). It is clear from Fig. 10b that the loss in shear capacity in these beams occurs due to local buckling effects early into the fire test. Then, additional losses due to strength degradation of the steel arise at a later stage. 
Failure of Beams 1 and 2 is initiated by web local buckling which starts early into the fire exposure. It is clear that the initiation of web local buckling occurs regardless of the beam configuration (bare beam or composite beam), since local buckling is a function of steel temperature and steel section properties. When the responses of Beams 1 and 2 are compared, it can be seen that the latter is much better than the former. This is due to the positive contribution of concrete slab to the sectional capacity, which enhances failure time of this beam. "Beam 2" fails at $16 \mathrm{~min}$ (when the web temperature is $780^{\circ} \mathrm{C}$ ), as compared to the failure of "Beam 1" in 11.6 min (when the web temperature is $560^{\circ} \mathrm{C}$ ) as shown in Table 2 .

The progression of mid-span deflections with the fire exposure time is plotted in Fig. 11. The initial deflection in the composite beam (Beam 2) is slightly lower than that of the bare steel beam (Beam 1). This can be attributed to the additional stiffness provided by the concrete slab. Then, both beams undergo a steady mid-span deflection growth until the steel temperature starts to increase. Once the steel temperature reaches $500^{\circ} \mathrm{C}$, the strength and elastic modulus of steel start to degrade rapidly and the neutral axis of Beams 1 and 2 start shifting upwards to balance internal tensile and compressive stresses. At this point, "Beam 1" experiences faster and larger amount of deflection growth as compared to that "Beam 2", due to absence of the concrete slab. This leads to an earlier failure of "Beam 1" at about 11.6 min, when the temperature in web reaches $560^{\circ} \mathrm{C}$. On the other hand, the presence of the cooler concrete slab, in "Beam 2", continues to contribute in resisting the applied forces and aids in delaying failure of this beam. The mid-span deflection of "Beam 2" stabilizes before the beam fails at $16 \mathrm{~min}$, after web temperature reaches $780^{\circ} \mathrm{C}$. "Beam 2" fails when the applied shear force exceeds its degrading shear capacity due to local buckling and strength degradation. It should be noted that the midspan deflection of "Beam 2" at failure (16 min) is $150 \mathrm{~mm}$, which is significantly lower than that 
obtained for the steel beam "Beam 1" that reaches $200 \mathrm{~mm}$ at $11.6 \mathrm{~min}$. It can be seen that this occurrence of local buckling does not significantly affect the mid-span deflection of fire exposed beams since it occurs locally in the steel web. However, local buckling can lead to significant loss of shear capacity.

\subsection{Effect of strength properties (Grade) of steel}

In order to study the effect of mechanical properties (Grade) of steel on web local buckling in fire exposed steel beams, an additional "Beam 3" is analyzed using the above developed model. "Beam 3" has the same geometrical features, loading set-up and boundary conditions as "Beam 1", but is made of Grade 36 steel $\left(f_{y}=250 \mathrm{MPa}\right)$ instead of Grade 50 (345 $\mathrm{MPa})$.

The change in strength (Grade) of steel does not influence the thermal properties of steel and, hence, temperature evolution in Beams 1 and 3 is similar. However, the strength analysis of these beams produces quite different responses under fire conditions. Figure 12 shows the degradation of moment and shear capacity of Beams 1 and 3 with fire exposure time. It is clear that room temperature flexural and shear capacity of "Beam 3" is lower than that of "Beam 1" due to the lower strength (Grade) of steel used. As discussed above, the flexural failure of "Beam 1” occurs at $14 \mathrm{~min}$, when the average steel temperature reach as $630^{\circ} \mathrm{C}$. Similar to "Beam 1”, “Beam 3" also fails at 14 min. This can be attributed to several factors, for instance both beams were subjected to loadings equivalent to $50 \%$ of their room temperature moment capacity. In addition, since temperature evolution in both beams is independent of the steel grade and strength properties, and both steel grades degrade at the same rate, these beams fail at identical steel temperatures and times. 
Figure 12b shows the shear response of Beams 1 and 3 when exposed to fire conditions. It can be seen that the initial shear capacity of "Beam 3" is smaller than that of "Beam 1", due to the lower yield strength. It can also be seen that the effect of web local buckling is less apparent in "Beam 3" than in "Beam 1". Since the web local buckling limit state is a function of $\left(\sqrt{E / f_{y}}\right)$, a lower yield strength $\left(f_{y}\right)$ increases the limiting value for local buckling (see Fig. 13). To illustrate this, the web cross-sectional slenderness of Beams 1 and $3\left(\lambda_{w}=57.8\right)$ is compared against the compactness limit $\left(\lambda_{p}\right)$ of steel with yield strengths $345 \mathrm{MPa}\left(\lambda_{p}=1.10 \sqrt{\frac{k_{v} E}{f_{y}}}=59.24\right)$ and $250 \mathrm{MPa}\left(\lambda_{p}=1.10 \sqrt{\frac{k_{v} E}{f_{y}}}=69.6\right)$. It is clear that the local buckling limit of $250 \mathrm{MPa}$ steel is 17.8\% higher than that of steel made of yield strength of $345 \mathrm{MPa}$ steel. Thus, for identical steel sections made of $250 \mathrm{MPa}$ and $345 \mathrm{MPa}$ steel, web buckling becomes less relevant for failure of the beam made of $250 \mathrm{MPa}$ steel when subjected to similar conditions and loading levels.

To further illustrate this feature, web slenderness of Beams 1 and 3 exceeds the compactness limits of Grade 345 and $250 \mathrm{MPa}$ steel at 150 and $400^{\circ} \mathrm{C}$, respectively (see Fig. 13). Thus, “Beam 1" experiences web local buckling at lower steel temperatures and earlier than “Beam 3”. It can also be seen from Fig. 13 that web local buckling of “Beam 3” occurs at $400^{\circ} \mathrm{C}$, which is the same temperature at which the strength starts to degrade. This is the opposite to “Beam 1" for which web local buckling occurs at $150^{\circ} \mathrm{C}$, but strength degradation occurs at $400^{\circ} \mathrm{C}$.

Figure 14 shows the evolution of the mid-span defection of Beams 1 and 3. As expected, “Beam 3" experiences larger initial deflection than "Beam 1", due to the lower yield strength. Then, like for "Beam 1", “Beam 3” also undergoes steady deflection levels at the start of fire 
analysis. Then, deflection levels in both beams start to increase as the steel temperature rises. Once local buckling and strength degradation effect take place, the mid-span deflection of "Beam 3" increases at faster pace than mid-span deflection of "Beam 1". "Beam 3" exceeds the allowable deflection limit at about 12 min, while "Beam 1" exceeds it at 13.8 min. Table 3 shows failure times and temperature in the web and flanges of these beams.

\subsection{Effect of fire insulation}

In order to study the effect of fire insulation on the shear response and local instability of fire exposed steel beams, four additional beams (Beams 4, 5, 6 and 7) were analyzed using the developed finite element model. Beams 4, 5, 6 and 7 are replicates of "Beam 1" but protected with 12.5, 19, 25 and $50 \mathrm{~mm}$ thick vermiculite/gypsum (VG) insulation, respectively.

A comparison between the temperature evolution in beams with different insulation thicknesses is plotted in Fig. 15. In the first few minutes of fire exposure, all four insulated steel beams experience a slight temperature rise. However, beyond that, the temperature rise in the web increases as a function of insulation thickness and, naturally, a higher insulation thickness leads to a lower steel temperature.

A lower temperature in insulated beams leads to a slower degradation in strength and stiffness properties. This delays the occurrence of local buckling as well as the moment and shear capacity degradation (see Fig. 16a). The moment capacity starts to degrade at 20, 26 and 33 min for Beams 4, 5 and 6, respectively; a significant delay than that in "Beam 1", for which the degradation of moment capacity starts at 9 min. Once the moment capacity decreases to the level of the bending moment due to applied loading, failure occurs. Under flexural limit state, the failure of Beams 4, 5 and 6 occurs at 39, 65 and 80 min, respectively. It should be noted that the moment and shear capacity of "Beam 7" remain intact during the entire fire exposure duration, 
since the cross-sectional temperature (web and flanges) remains below $400^{\circ} \mathrm{C}$ due to the much thicker fire insulation.

Local instabilities and degradation in shear capacity of the insulated beams starts once the steel temperature is in the range of $150-400^{\circ} \mathrm{C}$. The effect of local buckling of the web on the shear capacity is illustrated in Fig. 16b where the onset of web local buckling occurs at 8.2, 10, 13 and 22 min for Beams 4, 5, 6 and 7, and the shear capacity starts to degrade at 5, 10, 13.4 and 16.2 min for Beams 1, 4, 5 and 6. In addition, Fig. 16b clearly shows how the onset of web local buckling increase the rate of degradation of shear capacity and accelerates failure in the beams. When temperature-induced web local buckling is neglected (as in the fire provisions of current codes and standards), Beams 4, 5 and 6 fail at 37, 55 and 67 min, respectively. However, when temperature-induced local buckling of web is accounted for, failure of these beams occur at earlier times, namely at 34, 39 and 55 min, respectively. In general, the onset of web local buckling occurs when the web temperature reaches $150^{\circ} \mathrm{C}$. These temperature-induced web local buckling effects can lead to higher shear capacity degradation of steel beams with slender webs.

Further, both Beams 5 and 6 achieved 1-hour fire rating, as per the prescriptive criterion for the flexural limit state. However, these beams do not yield 1-hour fire rating under shear limit state when local buckling is accounted for. Therefore, shear failure can significantly lower failure times which in turn may lead to an unconservative fire resistance under certain scenarios.

Figure 17 compares the obtained mid-span deflections in Beams 1, 4, 5, 6 and 7 to the British Standard BS-476 deflection limit state [23]. In all beams, the mid-span deflections remain low at the initial stages of fire exposure. Then, they gradually increase with increasing fire exposure time. In general, Beams 4 and 5, with thinner fire insulation, undergo larger deflections 
than Beams 6 and 7 throughout fire. Failure times of these beams are also given in Table 4 . Overall, failure in this group of beams occurs primarily in shear limit state (as shown in Table 4). This failure mainly results from web local buckling since the onset of web local buckling occurs when web temperature is in the range of $150-200^{\circ} \mathrm{C}$, at $8.2,10,13$ and 22 min for Beams 4, 5, 6 and 7, and shear capacity starts to degrade at 10, 13.4 and $16.2 \mathrm{~min}$.

\subsection{CONCLUSIONS}

A three-dimensional nonlinear finite element model, capable of accounting for critical factors that influence local instability in fire exposed steel beams is developed. The effect of critical factors governing temperature-induced local buckling such as effect of beam-slab interaction, strength properties (Grade) of steel, and presence of fire insulation on the response of fire exposed steel beams is studied herein. Based on the results of the analysis presented herein, the following conclusion can be drawn:

1. Onset of temperature-induced local buckling in web can induce stability related failure in steel beams. This effect, in combination with temperature-induced strength loss, can accelerate shear failure before attaining flexural capacity.

2. Presence of concrete slab not only enhances sectional capacity but also aid in stabilizing fire exposed steel beams by counterbalancing adverse effects of temperature-induced web local buckling.

3. The strength (Grade) of steel determines the temperature at which local buckling occurs in fire exposed steel beams. In steel beams made of Grade $345 \mathrm{MPa}$ steel, local buckling can occur when steel temperature reaches $150^{\circ} \mathrm{C}$, while in steel beams made of Grade $250 \mathrm{MPa}$, local buckling occur at much higher steel temperatures (around $400^{\circ} \mathrm{C}$ ). 
The above developed model, although gives good prediction of local buckling in steel beams, can be further validated to enhance its applicability over wide range of scenarios. For this purpose, an experimental program involving full scale fire tests on composite steel beams subjected to high shear loading is currently under way at Michigan State University. Results from these tests will be utilized to further validate the finite element model and undertake additional parametric studies, which will be used to develop guidelines for predicting temperature induced local buckling in steel beams and girders.

\section{ACKNOWLEDGMENTS}

This material is based upon the work supported by the National Science Foundation under Grant number CMMI-1068621 to Michigan State University. Any opinions, findings, and conclusions or recommendations expressed in this paper are those of the authors and do not necessarily reflect the views of the sponsors.

\section{REFERENCES}

[1] Kodur VKR, Naser MZ. Effect of Shear on Fire Response of Steel Beams. Journal of Constructional Steel Research 2013;97:48-58 .

[2] Garlock M, Paya-Zaforteza I, Kodur VKR, Gu L. Fire hazard in bridges: Review, assessment and repair strategies. Engineering Structures 2012;35:89-98.

[3] Hall WJ. Shear deflection of wide flange steel beams in the plastic range. Wright Air Development Center. Urbana, IL: University of Illinois. 1954.

[4] Kodur VKR, Naser MZ. Effect of shear on stability of steel beams under fire conditions. Proceedings of the annual Structural Stability Research Council. Toronto, Canada, March 25-28, 2014.

[5] Wang Y, Kodur V. Research Toward Use of Unprotected Steel Structures. J. Struct. Eng. 2000;126:1442-1450. 
[6] Wang W, Kodur VKR, Yang X, Li G. Experimental study on local buckling of axially compressed steel stub columns at elevated temperatures. Thin-Walled Structures;2014;82:33-45

[7] Uy B, Bradford MA. Local buckling of cold formed steel in composite structural elements at elevated temperature. J Constr Steel Res 1995;34(1):53-73.

[8] Zhao B, Kruppa J, Fire resistance of composite slabs with profiled steel sheet and of composite steel concrete beams Part 2: Composite beams, Centre technique industriel de la construction métallique, 1992.

[9] Heidarpour A, Bradford MA. Local buckling and slenderness limits for steel webs under combined bending, compression and shear at elevated tempera- tures. Thin Walled Struct 2008;46(2):128-46.

[10] AISC. Specification for structural steel buildings 360-11. American Institute of Steel Construction Inc.; Chicago, IL 2011.

[11] EN 1994-1-1. Eurocode 4 - design of composite steel concrete structures, part 1.1: general rules and rules for buildings, 2004.

[12] Johnson RP, Willmington RT. Vertical shear in continuous composite beams. Proc. Inst. Civ. Eng. 1972;53:189-205.

[13] Nie J, Xiao Y, Chen L. Experimental studies on shear strength of steel-concrete composite beams. J struct. Eng. 2004;10: 1206-1213.Vasdravellis G, Uy B, Shear Strength and Moment-Shear Interaction in Steel-Concrete Composite Beams. J. Struct. Eng. 2014;140.

[14] ANSYS. Finite element computer code. Version 14. Canonsburg (PA): ANSYS, Inc; 2011. 
[15] Eurocode 3. Design of steel structures, Part1-2: General rules-structural fire design, Document CEN, European Committee for Standardization, UK in, 2005.

[16] Eurocode 2. Design of concrete structures, Part1-2: general rules-structural fire design. ENV 1992-1-2. UK: CEN: European Committee for Standardization; 2004.

[17] Kodur V.K.R, Dwaikat M.M.S, Dwaikat M.B, "High-temperature properties of concrete for fire resistance modeling of structures ", ACI Materials Journal, V. 105, No. 5, pp. 517-527, 2008.

[18] Kodur, V., Dwaikat, M., and Fike, R. (2010). "High-Temperature Properties of Steel for Fire Resistance Modeling of Structures.” J. Mater. Civ. Eng., 22(5), 423-434.

[19] William K, Warnke E. Constitutive model for the triaxial behavior of concrete, in International Association for bridge and Structural Engineering 1975.

[20] Nie J, Xiao Y, Chen L. Experimental studies on shear strength of steel-concrete composite beams. J. Struct. Eng. 2004;10:1206-1213.

[21] Ollgaard JG, Slutter RG, Fisher JW. Shear strength of stud connectors in lightweight and normal weight concrete. Eng J AISC 1971;8:55-64.

[22] Comite Euro-International du Beton (CEB-FIP). CEB-FIP model code 1990. Bulletin D’Information No. 213/214 (Concrete Structures), Lausanne, Switzerland; 1993.

[23] British Standard Institution, Fire Tests on Building Materials and Structures. Part 20. Method of Determination of Fire Resistance of Elements of Constructions, BS 476, 1987.

[24] Kodur VKR, Fike RS. Guidelines for improving the standard fire resistance test specifications. Journal of ASTM International 2009;6:1-16. 
[25] Kodur VKR, Naser MZ, Pakala P, Varma A. Modeling the response of composite beam-slab assemblies exposed to fire. Journal of Constructional Steel Research 2013;80:163-173. 


\section{LIST OF TABLES:}

Table 1 Factors varied in parametric study on steel beams

Table 2 Failure in Beams 1 and 2

Table 3 Failure in beams with different properties of steel

Table 4 Failure in beams with different insulation thicknesses 
Table 1 Factors varied in parametric study on steel beams

\begin{tabular}{|c|c|c|c|}
\hline \multirow{2}{*}{ Beam } & \multicolumn{3}{|c|}{ Variable } \\
\cline { 2 - 4 } & Fire insulation & Strength properties (Grade) of steel & Composite action \\
\hline Beam 1 & None & Grade 50 $(345 \mathrm{MPa})$ & None \\
\hline Beam 2 & None & Grade 50 $(345 \mathrm{MPa})$ & Yes \\
\hline Beam 3 & None & Grade 36 $(250 \mathrm{MPa})$ & None \\
\hline Beam 4 & $12.5 \mathrm{~mm}$ & Grade 50 $(345 \mathrm{MPa})$ & None \\
\hline Beam 5 & $19 \mathrm{~mm}$ & Grade 50 $(345 \mathrm{MPa})$ & None \\
\hline Beam 6 & $25 \mathrm{~mm}$ & Grade 50 $(345 \mathrm{MPa})$ & None \\
\hline Beam 7 & $50 \mathrm{~mm}$ & Grade 50 $(345 \mathrm{MPa})$ & \\
\hline
\end{tabular}


Table 2 Failure in Beams 1 and 2

\begin{tabular}{|c|c|c|c|c|c|c|c|}
\hline \multirow{2}{*}{ Beam } & \multicolumn{4}{|c|}{ Failure time (min) } & \multicolumn{2}{|c|}{$\begin{array}{c}\text { Temp. at failure } \\
\left({ }^{\circ} \mathrm{C}\right)\end{array}$} & \multirow{2}{*}{ Failure mode } \\
\cline { 2 - 7 } & $\begin{array}{c}\text { Shear } \\
\text { (no WLB) }\end{array}$ & $\begin{array}{c}\text { Shear } \\
(\text { WLB) }\end{array}$ & Flexure & Deflection & Web & Flanges & \\
\hline Beam 1 & 13 & $\mathbf{1 1 . 6}$ & 14 & 13.8 & 560 & 540 & $\begin{array}{c}\text { Shear due to } \\
\text { local buckling }\end{array}$ \\
\hline Beam 2 & 18 & $\mathbf{1 6}$ & 28 & - & 780 & 690 & $\begin{array}{c}\text { Shear due to } \\
\text { local buckling }\end{array}$ \\
\hline
\end{tabular}

${ }^{*}$ Initiation of web local buckling occurs after 3 min of fire exposure (for Beams 1 and 2) 
Table 3 Failure in beams with different properties of steel

\begin{tabular}{|c|c|c|c|c|c|c|c|c|}
\hline \multirow{2}{*}{ Beam } & \multirow{2}{*}{$\begin{array}{c}\text { Grade of } \\
\text { steel } \\
\text { MPa } \\
\text { (ksi) }\end{array}$} & \multicolumn{4}{|c|}{ Failure time (min) } & \multicolumn{2}{|c|}{$\begin{array}{l}\text { Temp. at } \\
\text { failure }\left({ }^{\circ} \mathrm{C}\right)\end{array}$} & \multirow{2}{*}{$\begin{array}{l}\text { Failure } \\
\text { mode }\end{array}$} \\
\hline & & $\begin{array}{c}\text { Shear } \\
\text { (no WLB) }\end{array}$ & $\begin{array}{l}\text { Shear } \\
\text { (WLB) }\end{array}$ & Flexure & Deflection & Web & $\begin{array}{l}\text { Flang } \\
\text { es }\end{array}$ & \\
\hline Beam 1 & $345(50)$ & 13 & 11.6 & 14 & 13.8 & 560 & 540 & Shear \\
\hline Beam 3 & $250(36)$ & 11.6 & 11 & 13 & 12 & 550 & 500 & Shear \\
\hline
\end{tabular}

${ }^{*}$ Initiation of web local buckling at 3 and 8 min in web of Beams 1 and 3, respectively 
Table 4 Failure in beams with different insulation thicknesses

\begin{tabular}{|c|c|c|c|c|c|c|c|}
\hline \multirow{2}{*}{ Beam } & \multicolumn{4}{|c|}{ Failure time (min) } & \multicolumn{2}{c|}{$\begin{array}{c}\text { Temp. at failure } \\
\left({ }^{\circ} \mathrm{C}\right)\end{array}$} & \multirow{2}{*}{$\begin{array}{c}\text { Failure } \\
\text { mode }\end{array}$} \\
\cline { 2 - 7 } & $\begin{array}{c}\text { Shear } \\
\text { (no WLB) }\end{array}$ & $\begin{array}{c}\text { Shear } \\
(\text { WLB) }\end{array}$ & Flexure & Deflection & Web & Flanges & \\
\hline Beam 1 & 13 & $\mathbf{1 1 . 6}$ & 14 & 13.8 & 560 & 540 & Shear \\
\hline Beam 4 & 37 & $\mathbf{3 4}$ & 39 & - & 540 & 480 & Shear \\
\hline Beam 5 & 45 & $\mathbf{3 9}$ & 65 & - & 609 & 530 & Shear \\
\hline Beam 6 & 66 & $\mathbf{5 5}$ & 80 & - & 565 & 490 & Shear \\
\hline Beam 7 & No failure & No failure & No failure & - & - & - & No failure \\
\hline
\end{tabular}

* Initiation of web local buckling occurs at 8.2, 10, 13 and 22 min for Beams 4, 5, 6 and 7, respectively 


\section{LIST OF FIGURES:}

Fig. 1. Degradation of strength and stiffness properties of steel at elevated temperatures

Fig. 2. Variation of slenderness limits adopted in flexural and shear design at elevated temperatures

Fig. 3. Details of the developed finite element model for fire resistance analysis of beam-slab assembly

Fig. 4. Material properties used in the finite element model

Fig. 5. Tested beam used in validating the developed finite element model

Fig. 6. Comparison of predicted and measured temperature and deflections as a function of fire exposure time

Fig. 7. Degradation of moment and shear capacity in the tested beam [10]

Fig. 8. Applied loading set-up of analyzed beams

Fig. 9. Temperature in "Beam 5" as a function of fire exposure time

Fig. 10. Degradation of moment and shear capacity with fire exposure time in composite beam

Fig. 11. Mid-span deflection in "Beam 1" and "Beam 2" with fire exposure time

Fig. 12. Degradation of flexural and shear capacity in Beams 1 and 3 with fire exposure time

Fig. 13. Effect of properties of steel on local buckling of steel beam

Fig. 14. Comparison between mid-span deflections in "Beam 1" and "Beam 3"

Fig. 15. Temperature propagation in web of Beams 1, 4, 5, 6 and 7

Fig. 16. Degradation of flexural and shear capacity in Beams 1, 4, 5, 6 and 7 with exposure time

Fig. 17. Comparison between mid-span deflections of steel W-beams with different insulation thickness 


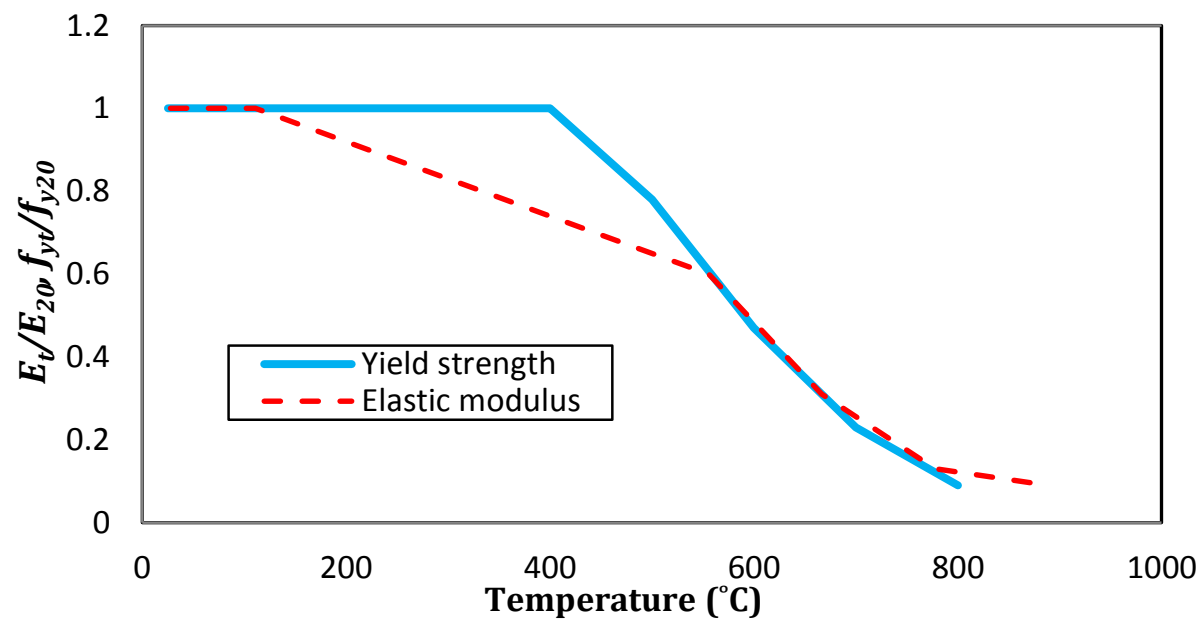

Fig. 1. Degradation of strength and stiffness properties of steel at elevated temperatures 


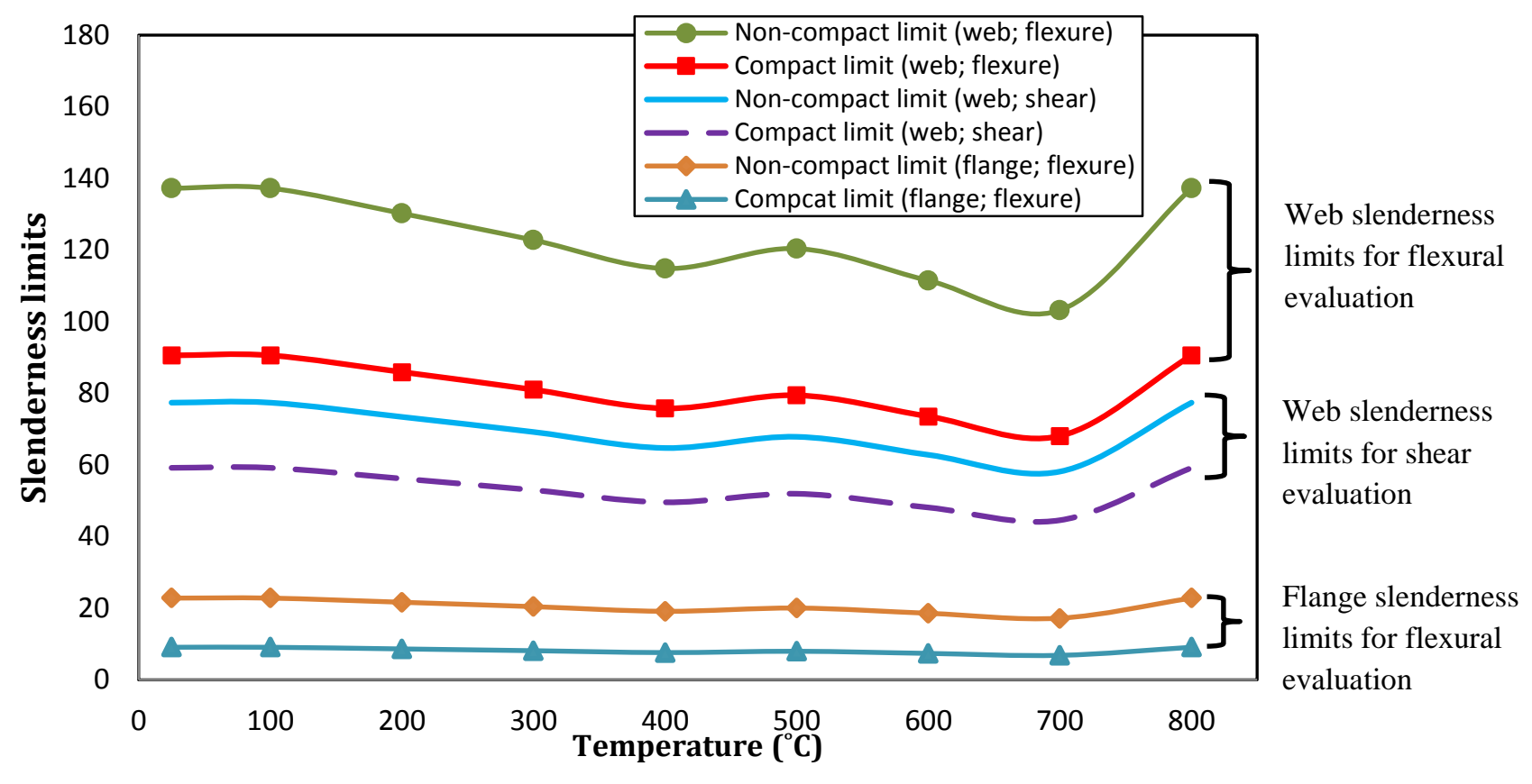

Fig. 2. Variation of slenderness limits adopted in flexural and shear design at elevated temperatures 

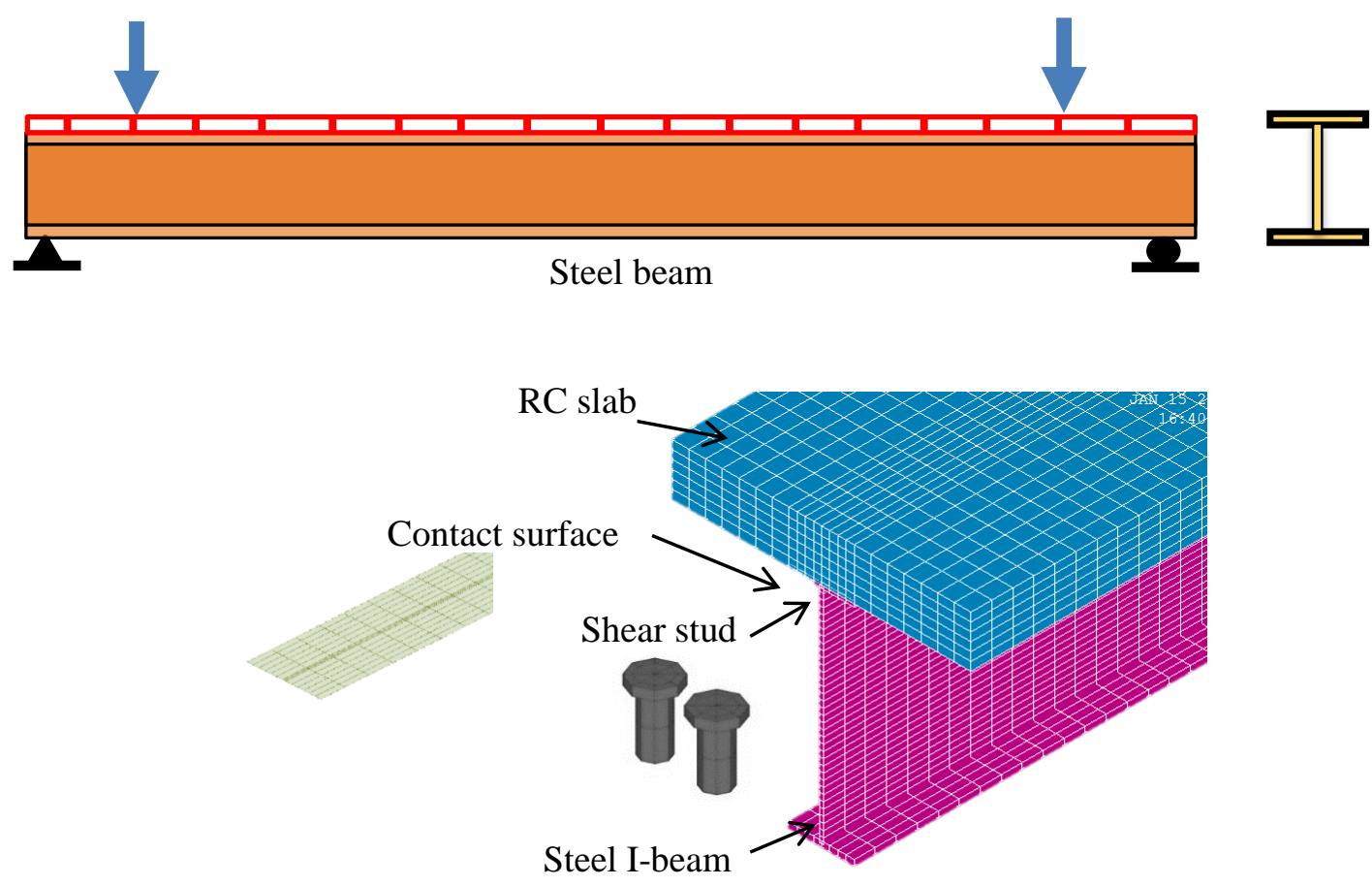

Fig. 3. Details of the developed finite element model for fire resistance analysis of beamslab assembly 


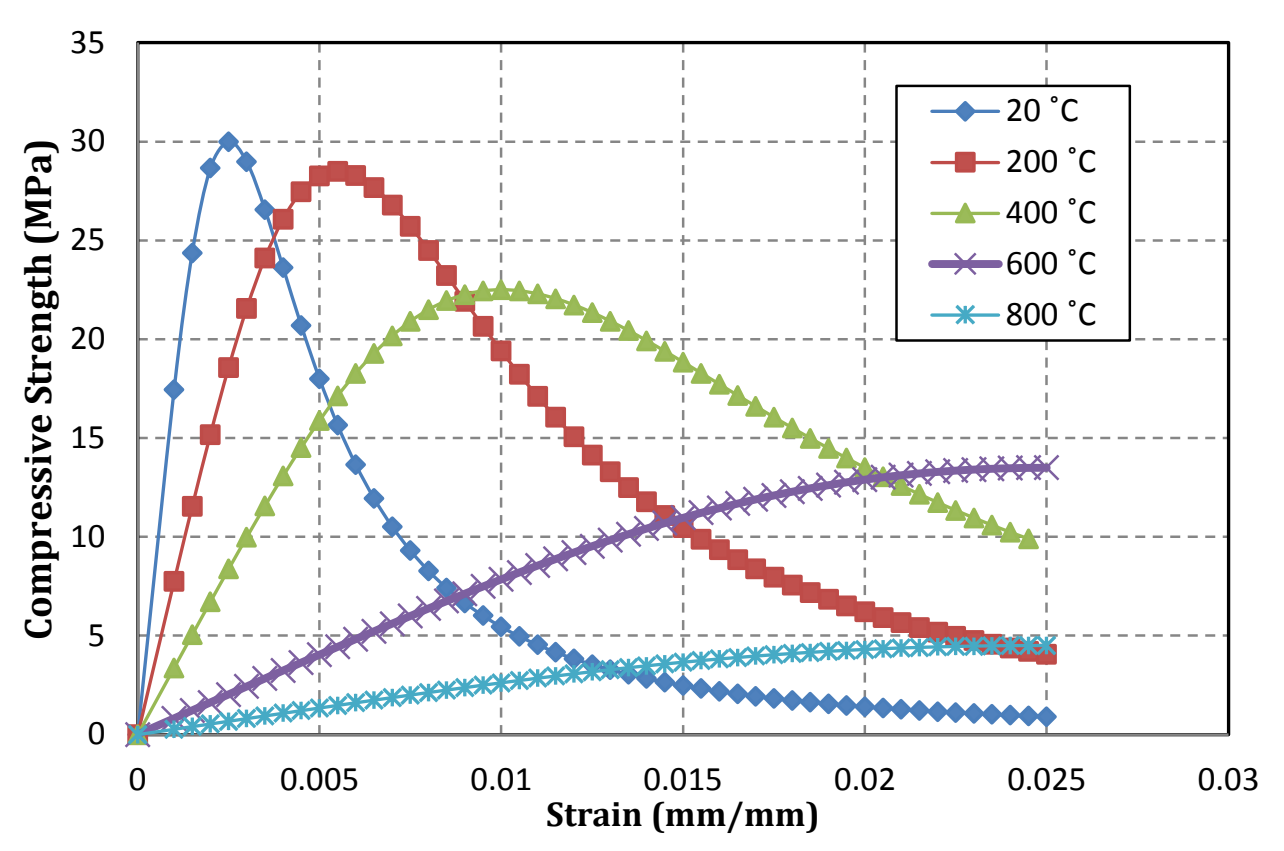

(a) Compressive strength of concrete at elevated temperature

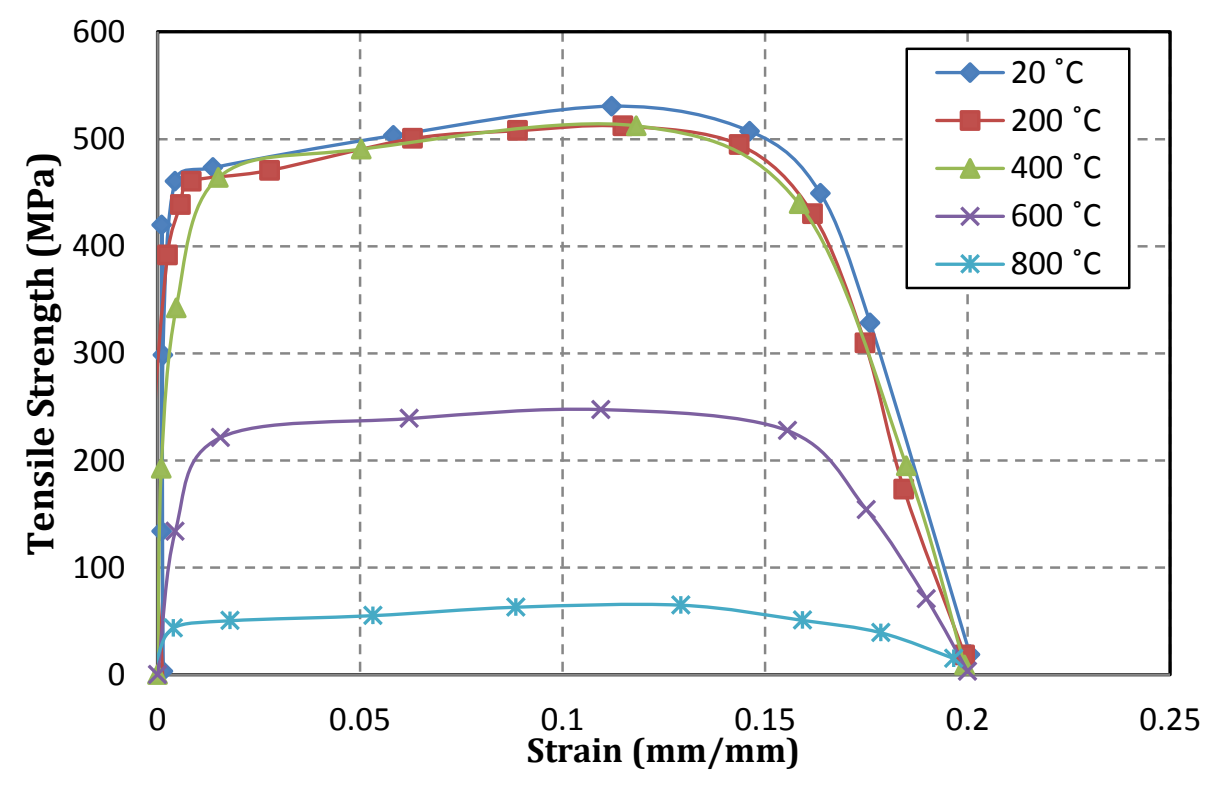

(b) Tensile strength of steel at elevated temperature

Fig. 4. Concrete and steel mechanical properties at elevated temperature 


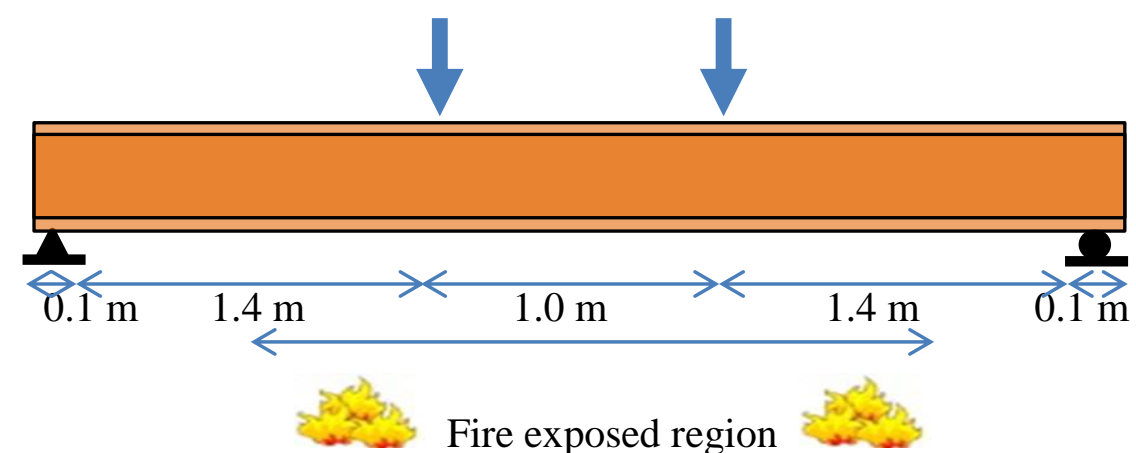

Fig. 5. Tested beam used in validating the developed finite element model 


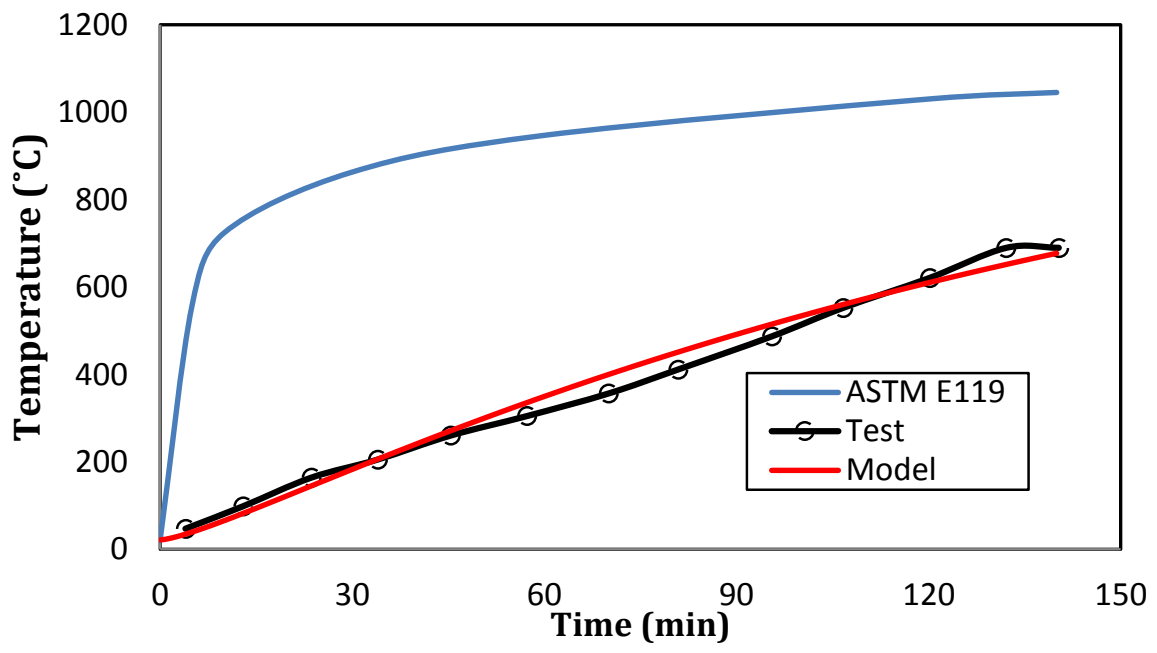

(a) Thermal response

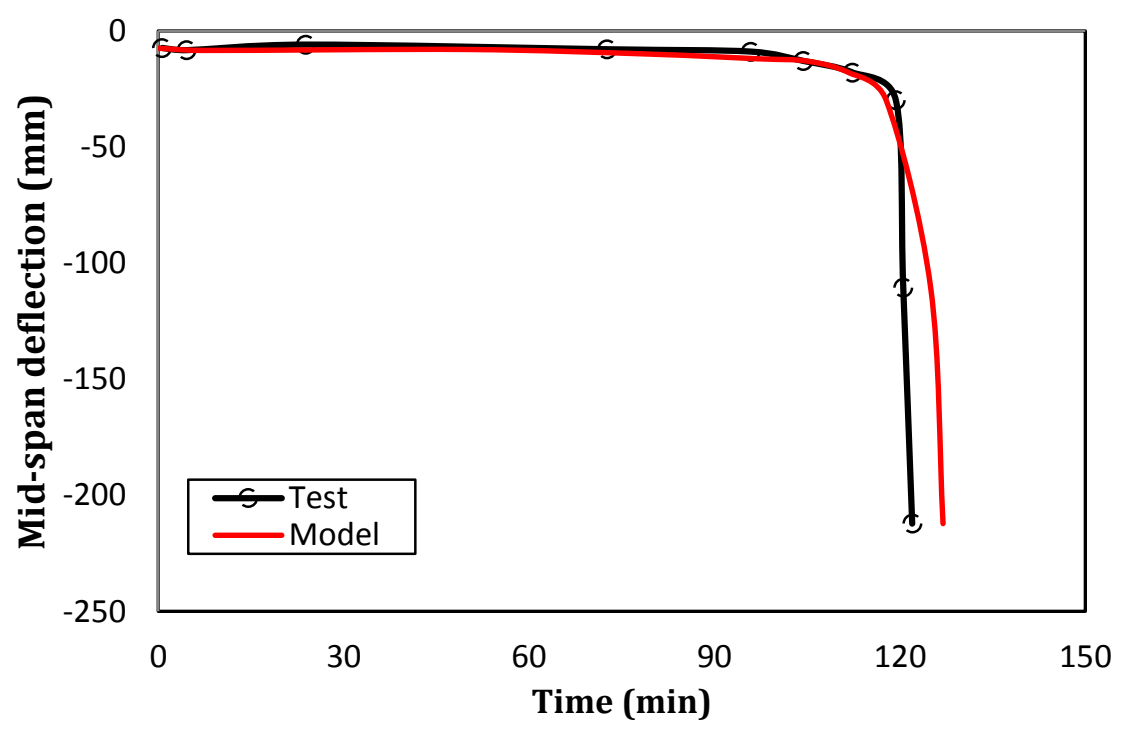

(b) Structural response

Fig. 6. Comparison of predicted and measured temperature and deflections as a function of fire exposure time; (a) average temperature propagation, (b) mid-span deflection 


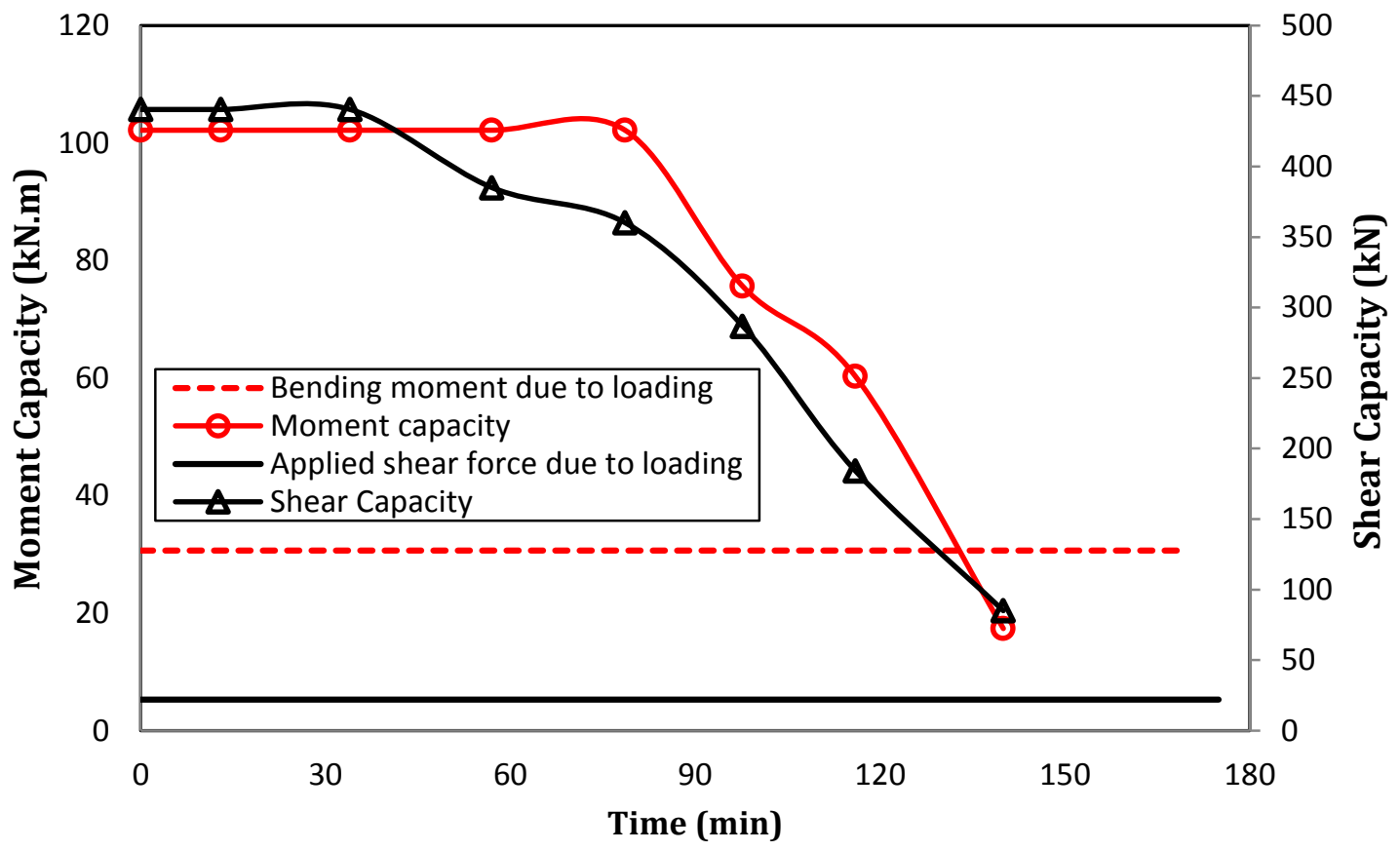

Fig. 7. Degradation of moment and shear capacity in the tested beam [10] 


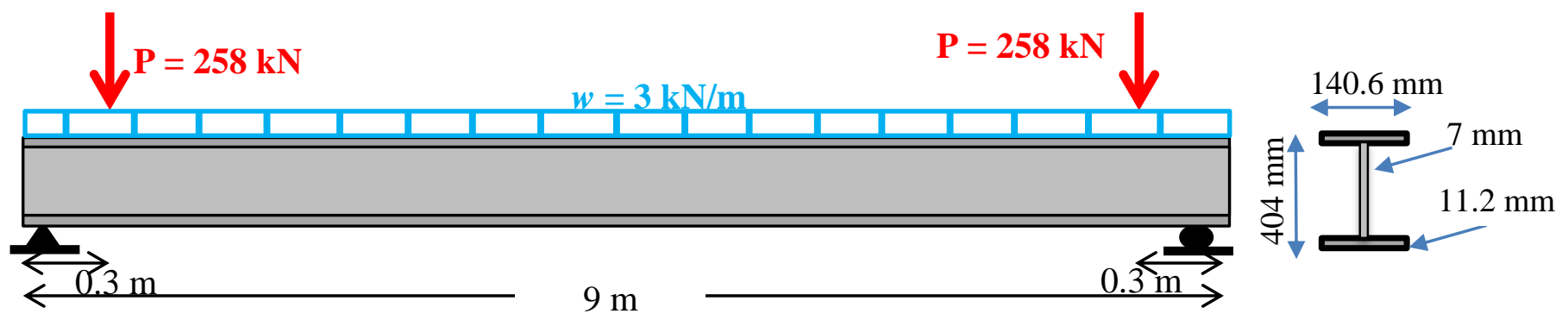

Fig. 8. Applied loading set-up of analyzed beams 


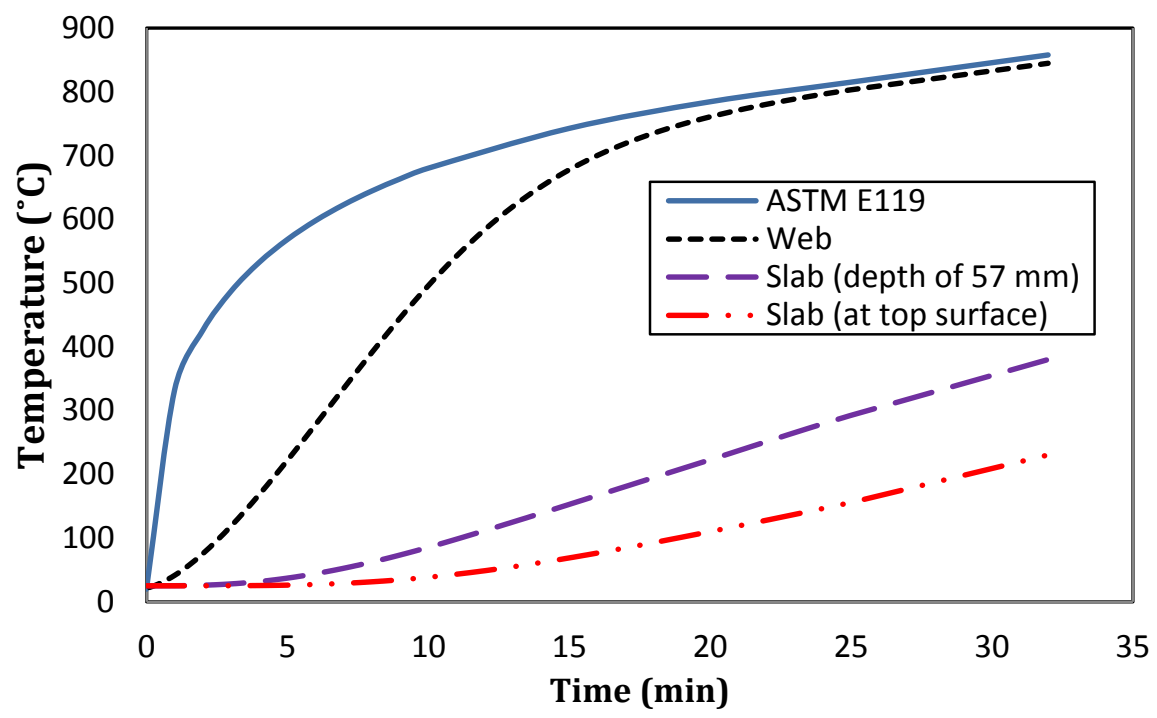

Fig. 9. Temperature in "Beam 5" as a function of fire exposure time 


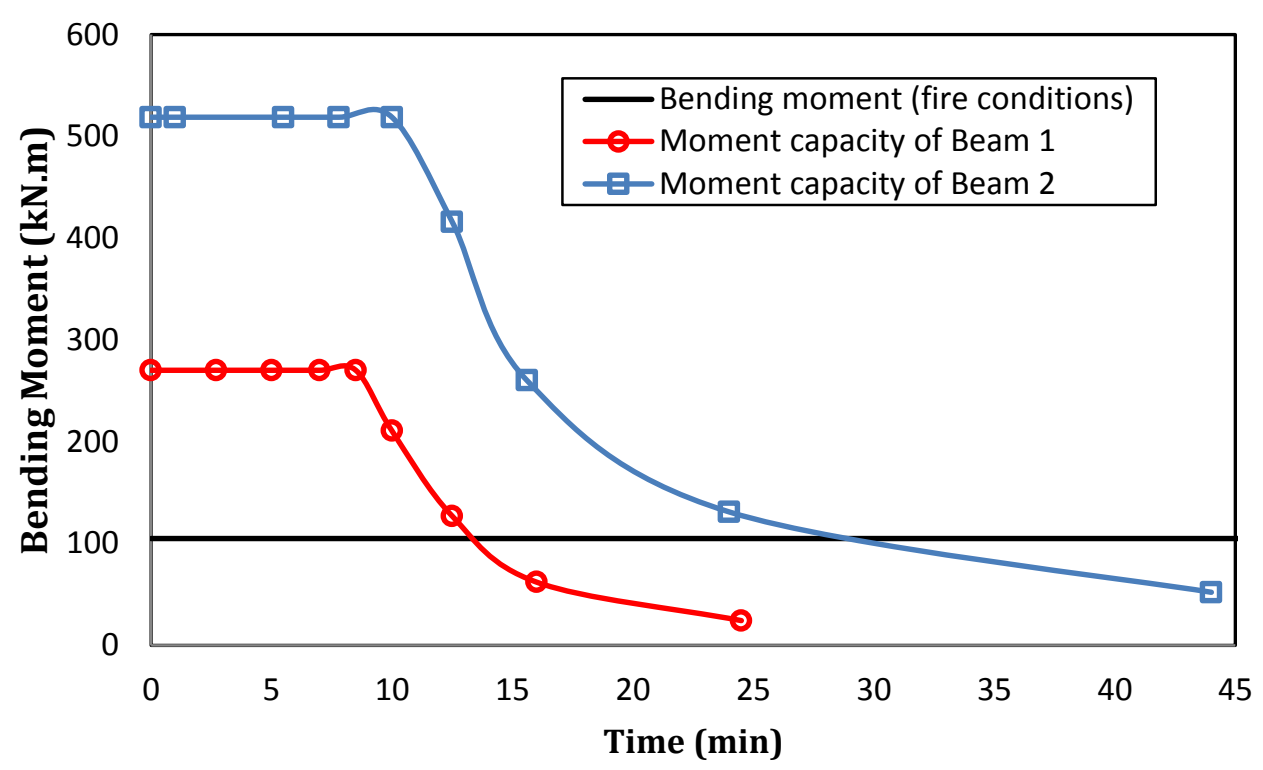

(a) Moment capacity

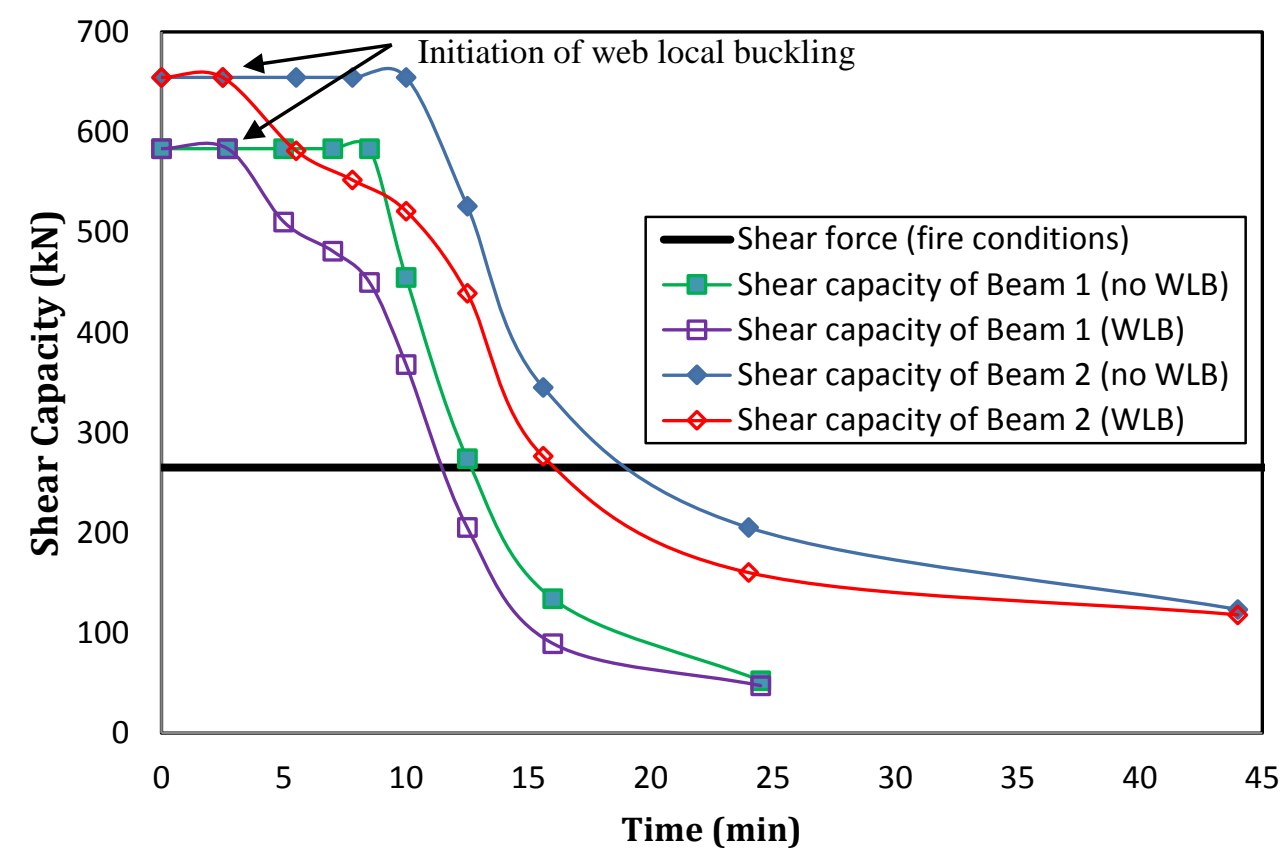

(b) Shear capacity

Fig. 10. Degradation of sectional capacity with fire exposure time in composite beam; (a) moment capacity, (b) shear capacity 


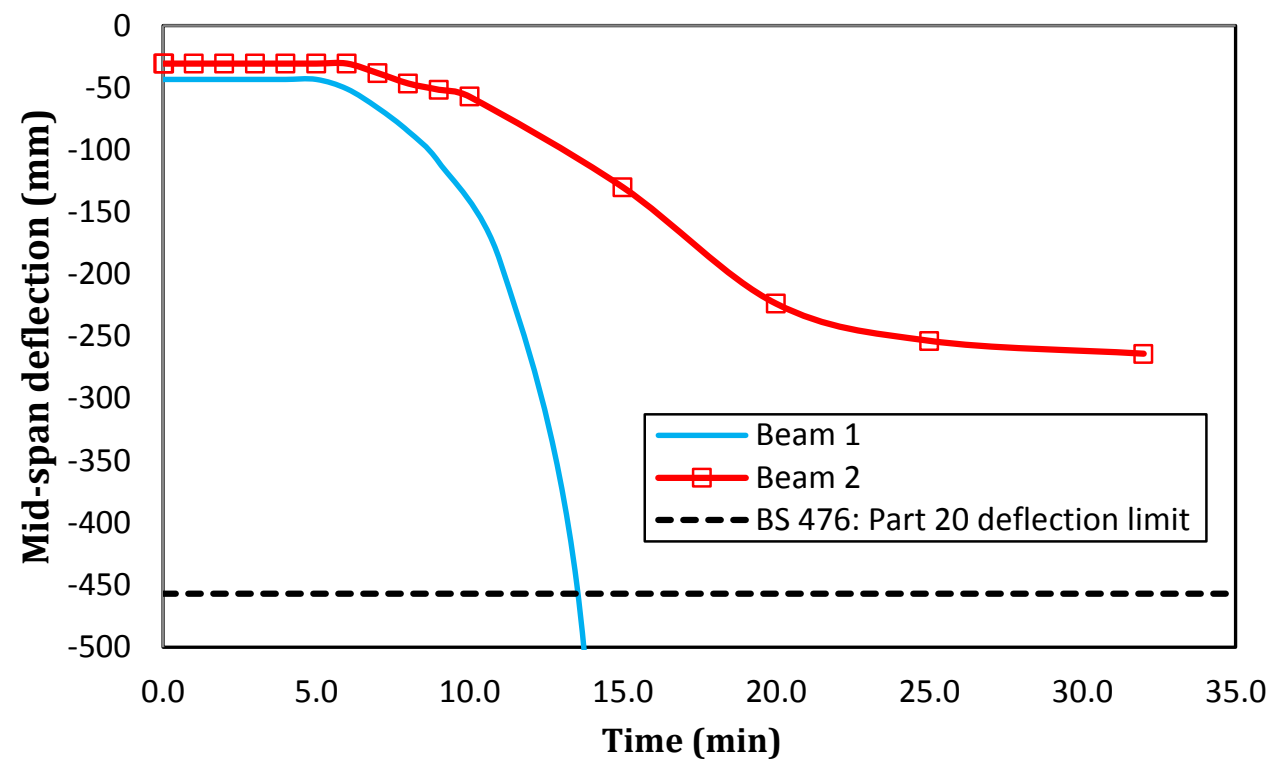

Fig. 11. Mid-span deflection in "Beam 1" and "Beam 2" with fire exposure time 


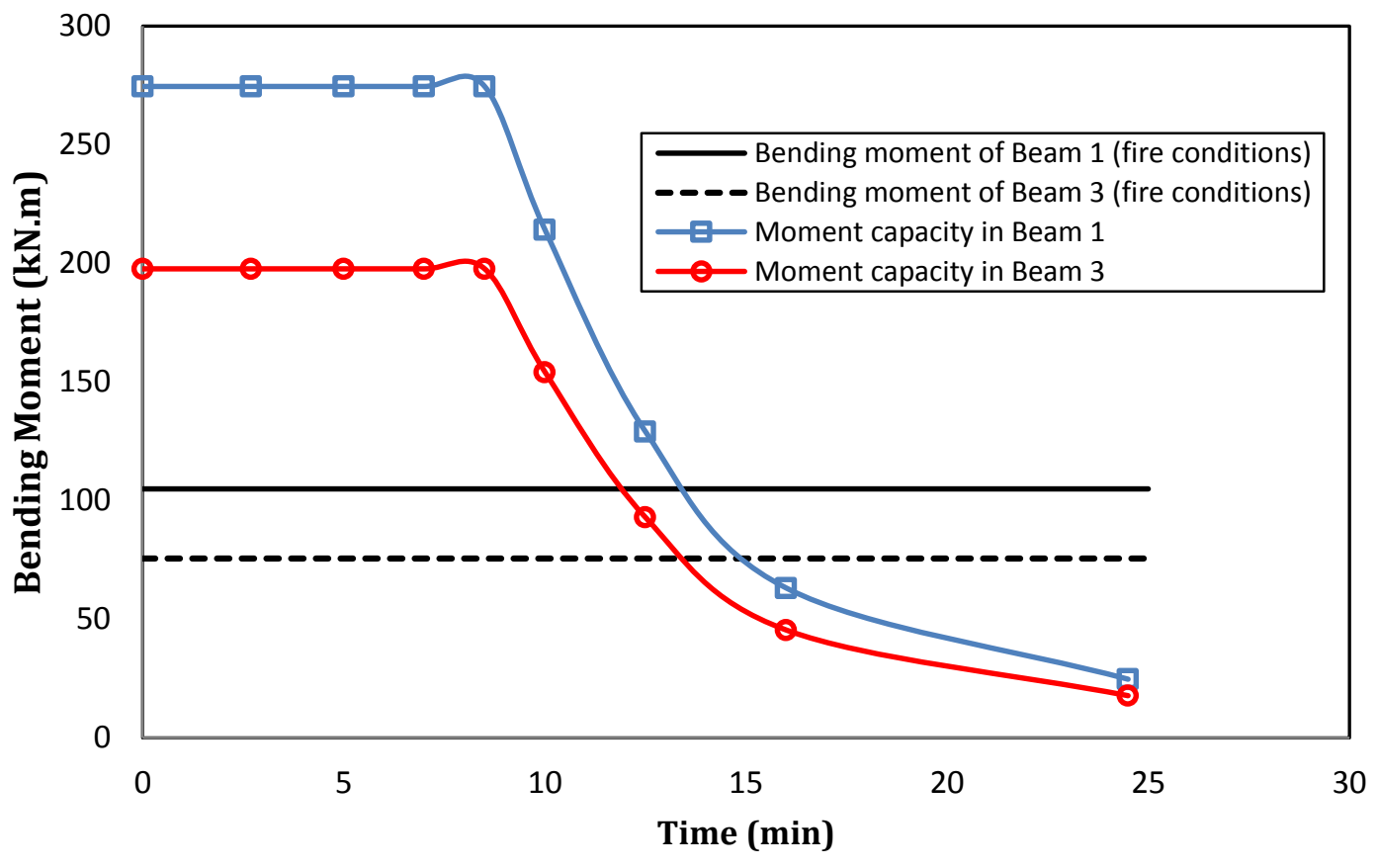

(a) Moment capacity

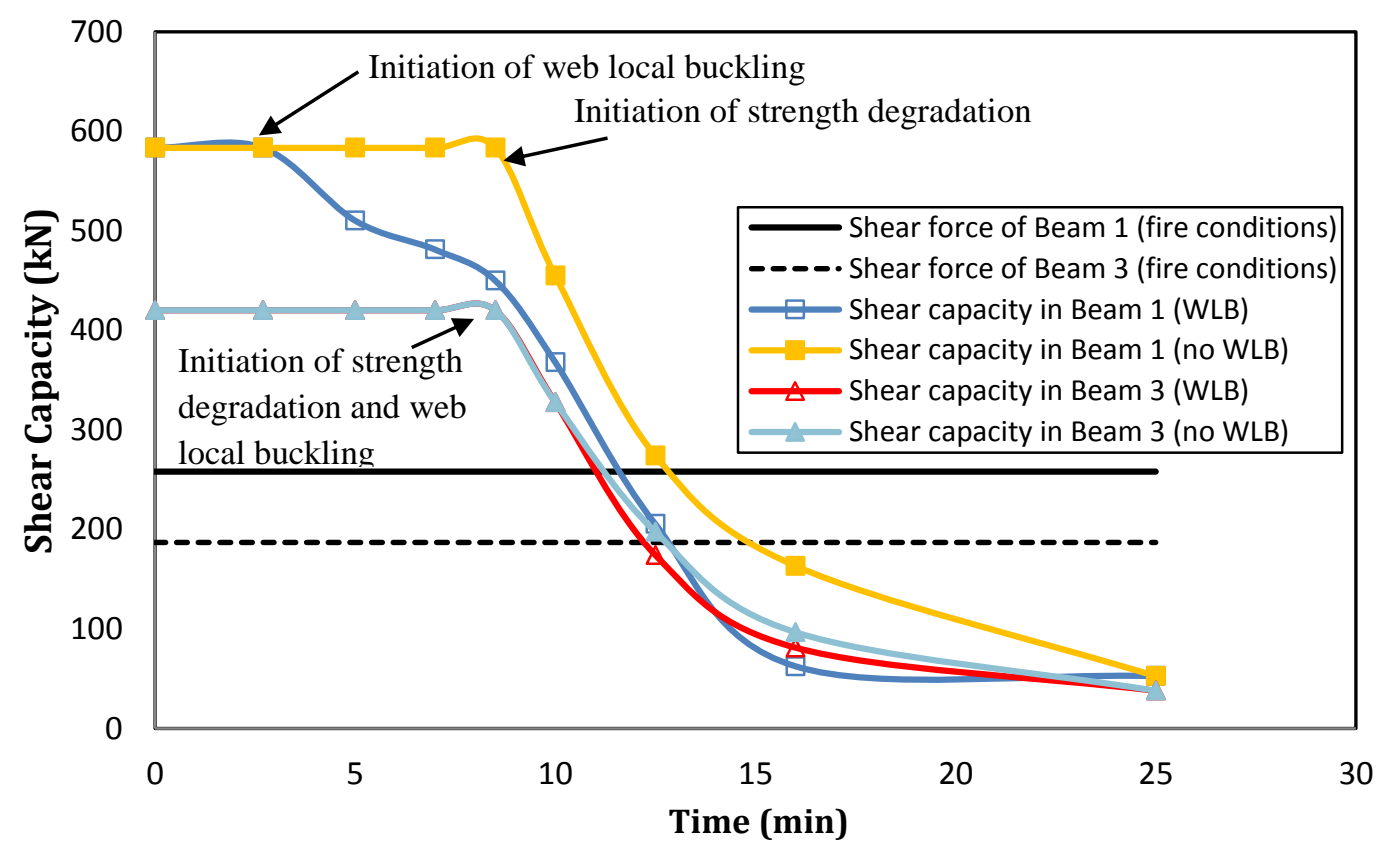

(b) Shear capacity

Fig. 12. Degradation of capacity in Beams 1 and 3 with fire exposure time; (a) moment capacity,

(b) shear capacity 


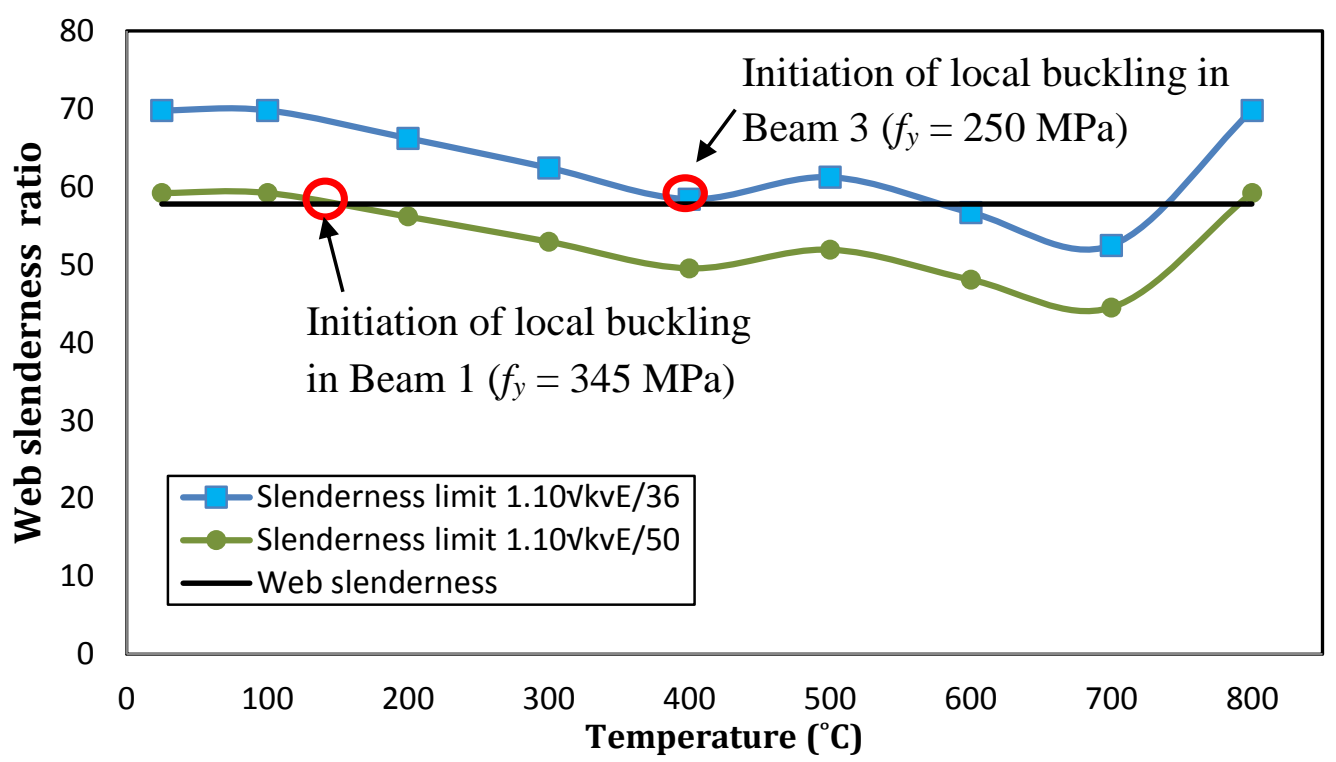

Fig. 13. Effect of properties of steel on local buckling of steel beam 


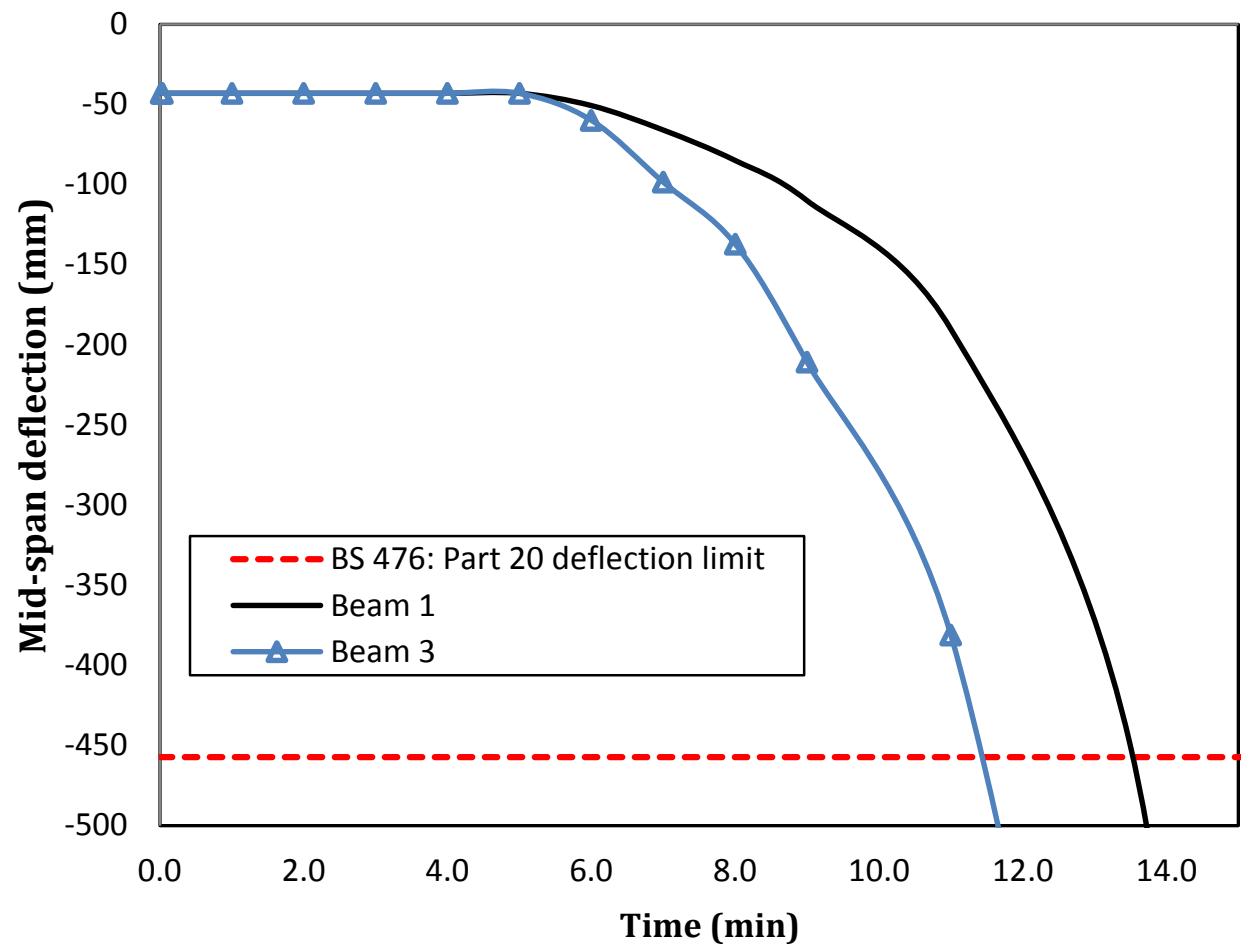

Fig. 14. Comparison between mid-span deflections in "Beam 1" and "Beam 3" 


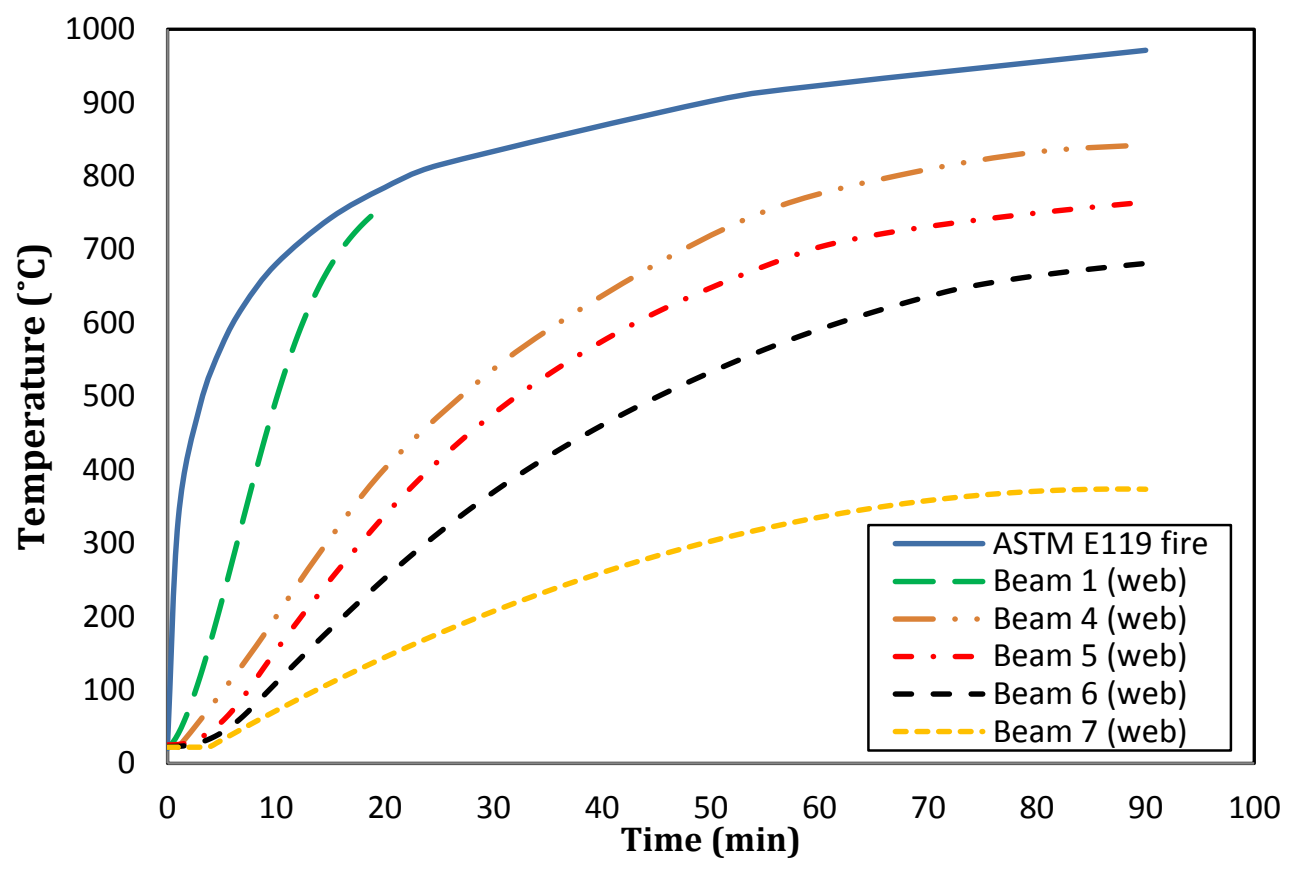

Fig. 15. Temperature propagation in web of Beams 1, 4, 5, 6 and 7 


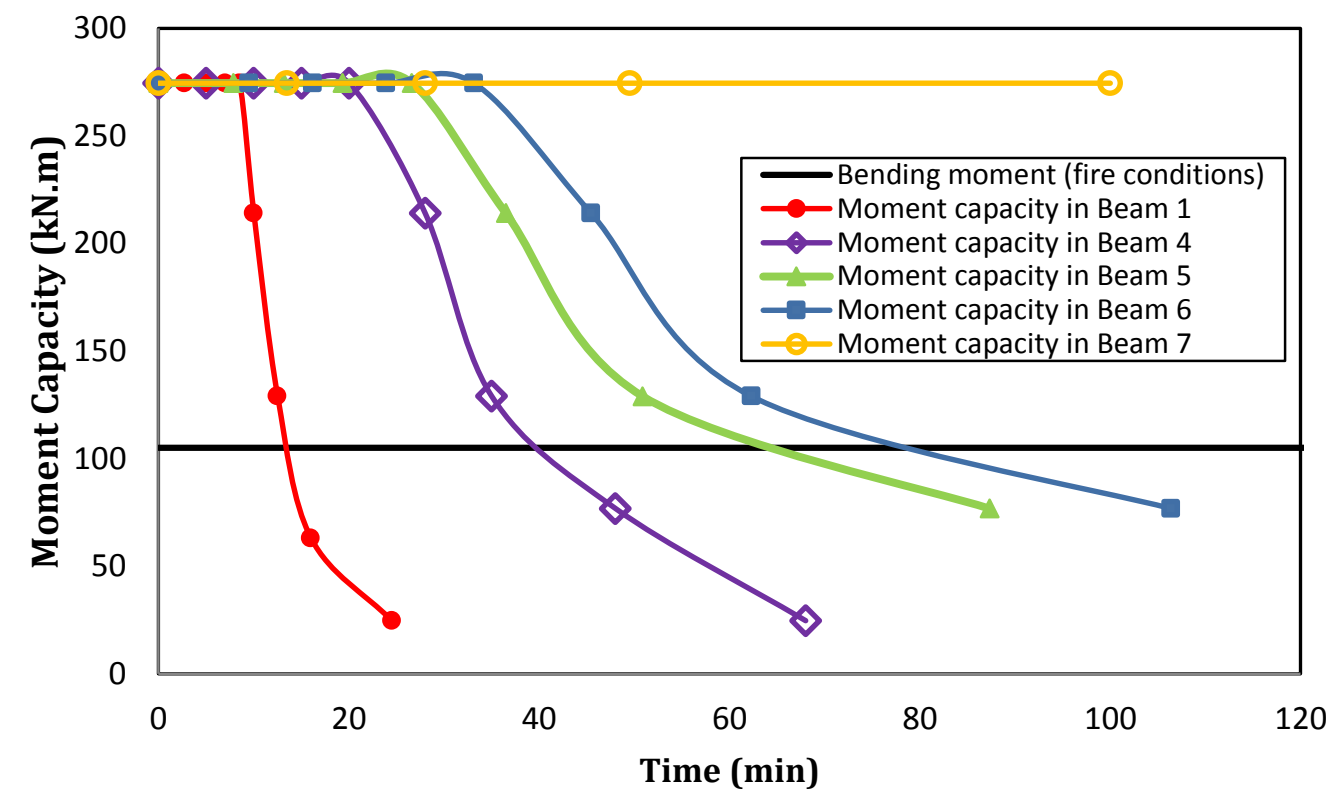

(a) Moment capacity

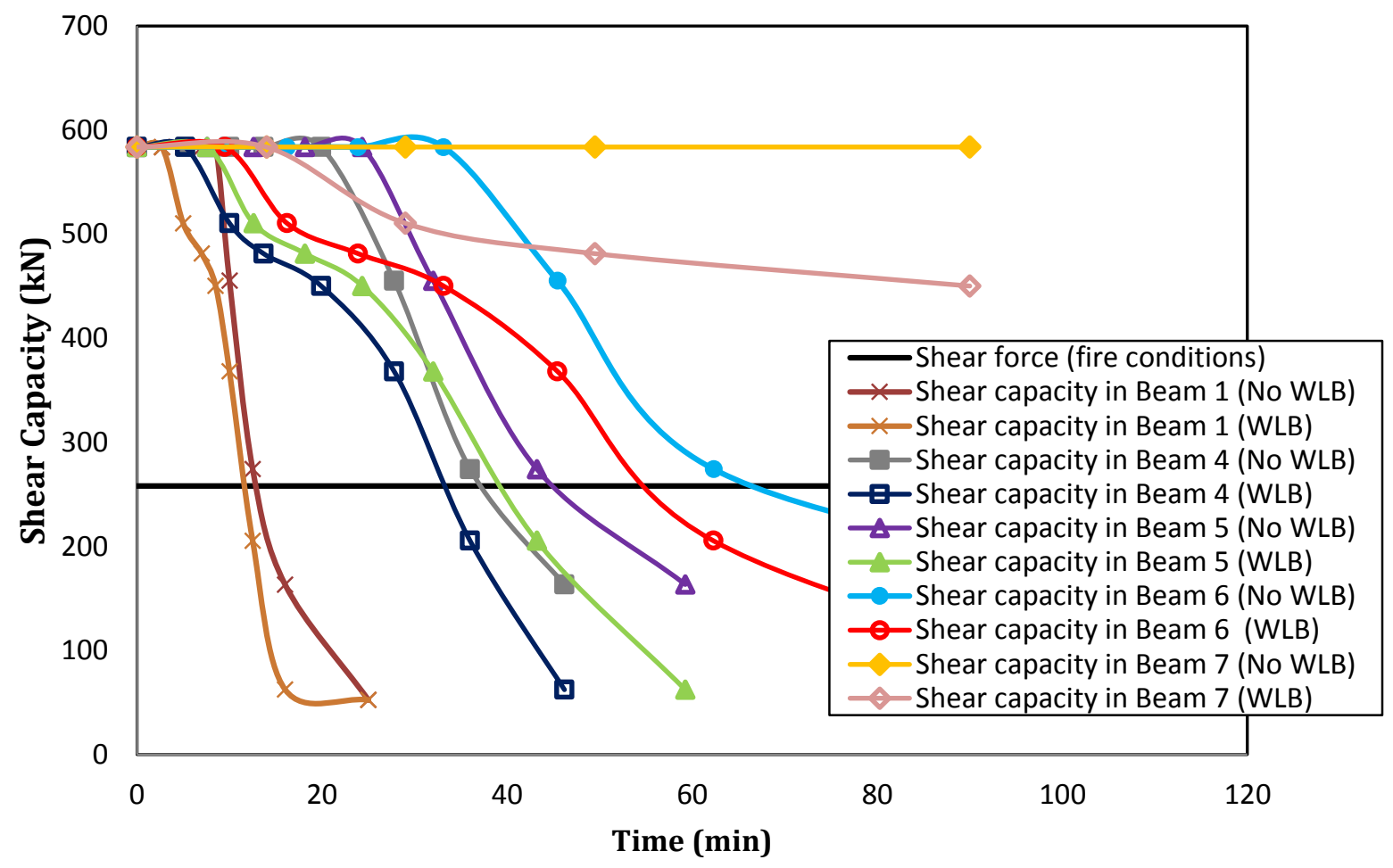

(b) Shear capacity

Fig. 16. Degradation of capacity in Beams 1, 4, 5, 6 and 7 with exposure time; (a) moment capacity, (b) shear capacity 


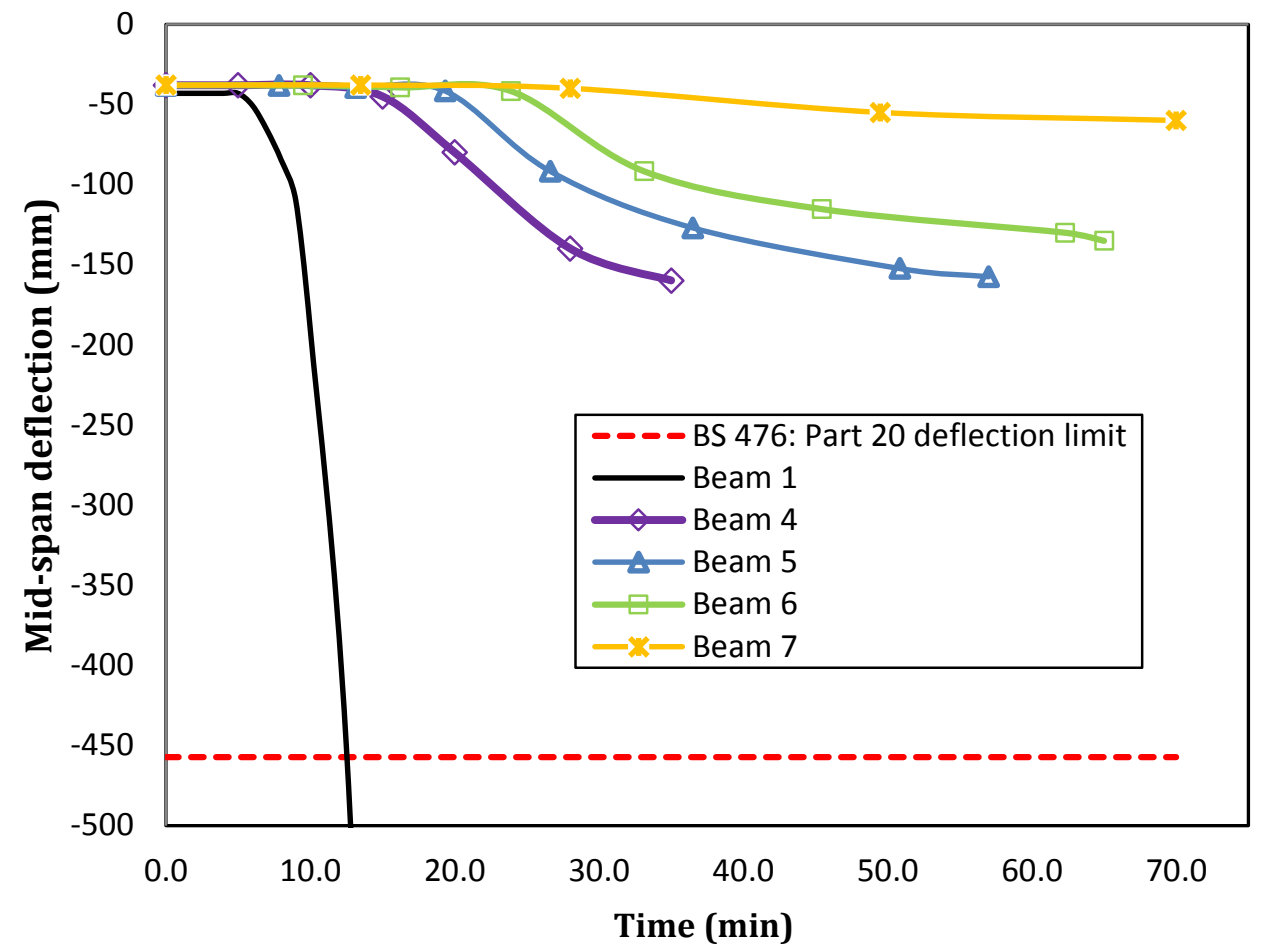

Fig. 17. Comparison between mid-span deflections of steel W-beams with different insulation thickness 